\title{
(Ac)cumulative Form in Pop-Rock Music
}

\author{
MARK SPICER
}

\begin{abstract}
This article examines a variety of compositional procedures that give rise to what the author defines as 'accumulative' and 'cumulative' forms in pop-rock music, formal processes which are directly linked to the rapid advances in recording technology that occurred mainly from the late 1960s to the 1980s. The article includes detailed transcriptions and analyses of pop-rock music across a wide range of styles and genres, from progressive rock to post-punk to techno.
\end{abstract}

J. Peter Burkholder has coined the term 'cumulative form' to describe an unusual compositional strategy in selected late nineteenth-century works, particularly in the music of Charles Ives. ${ }^{1}$ In typical large-scale eighteenth- and nineteenth-century tonal pieces (those in sonata form, for example), we expect the main theme to be stated intact at the outset - most often in the tonic key - and then subjected to various processes of fragmentation and development as the piece unfolds. In a cumulative form this typical order is reversed: thematic fragments are gradually introduced and developed, only to crystallize into a full-fledged presentation of the main theme in a climactic pay-off at the end of the piece. As Burkholder shows, prototypes of cumulative form can be found in symphonic works from early in the nineteenth century. Probably the most famous example is the finale of Beethoven's Ninth Symphony (1823), where fragments of the 'Ode to Joy' are introduced long before the theme makes its first complete appearance.

Burkholder's notion of cumulative form is limited to a fairly specific type of thematic process, and yet the adjective 'cumulative' brings to mind a wider range of possible formal strategies. In a 1993 essay entitled 'Coda as Culmination', Robert Morgan draws upon the aesthetic ideas of Richard Wagner as the basis for his interpretation of the first movement of Beethoven's 'Eroica' Symphony as a 'single, totally unified melody'.2 Following Wagner, Morgan stresses that musical works are first and foremost 'temporal forms . . , possessing an evolutionary character that makes their every moment a consequence of the preceding one, with the entire structure unfolding toward a final, predetermined conclusion'. ${ }^{3}$ This is

Earlier versions of portions of this article were presented at the Annual Meeting of the Society for Music Theory, Chapel Hill, NC, in December 1998, and to the Music Forum lecture series, City University of New York Graduate Center, in December 2001. I wish to thank Allen Forte, Walter Everett, John Covach, and the anonymous readers for this journal for their advice and criticism on earlier drafts.

1 See Burkholder, All Made of Tunes; also his 'Cumulative Form in Ives and Others' .

2 Morgan, 'Coda as Culmination'. Morgan quotes from Wagner's famous 1860 essay 'Music of the Future' ('Zukunfstmusik', in Gesammelte Schriften und Dichtungen (Leipzig, 1887-8), vol. 7).

3 Morgan, 'Coda as Culmination', 357. 
suggestive of a broader conception of cumulative form, one in which a variety of compositional procedures can contribute to our experience of a musical work as somehow always aiming toward a certain moment of culmination.

In this article, I will adapt this broader notion of cumulative form - along with its cousin 'accumulative' form, which I define below - to shed light on some similar procedures that have arisen within pop-rock music over the last thirty years or so. (To those who might object to the term 'pop-rock', I am simply using the term, as others have done, to include all of the myriad styles and genres that have arisen since the 1960s within both 'pop' and 'rock' traditions. ${ }^{4}$ ) From the outset, I should emphasize that form is a parameter that remains largely unexplored in popular music studies. ${ }^{5}$ Unfortunately, as with harmony, it is often assumed that the formal structure of most average three- or four-minute pop-rock songs is trite and simplistic, consisting of not much more than a predictable strophic alternation of verses, refrains, and choruses (with the occasional introduction or bridge thrown in for good measure). ${ }^{6}$ If we examine pop-rock songs more closely, we can often find their composers employing techniques of considerable sophistication in order to create interesting and unique formal structures that transcend these predictable boundaries. Examples of accumulative and cumulative forms can be found in songs written and recorded on both sides of the Atlantic, of course, and yet such forms seem to be particularly favoured by British pop-rock composers throughout the post-Beatles era. It is only appropriate then that I should draw all of my examples for this study from this rich and varied body of work.

4 As the story usually goes, 'pop' music is derivative and carefully calculated so as to appeal to the masses, while 'rock' music is grounded in 'authenticity' - in other words, rock songs represent genuine, personal statements without necessarily having a concern for mass appeal. In reality, however, the distinction between pop and rock is severely clouded in the majority of popular music. The term 'pop-rock' is therefore a convenient catch-all, and nothing more. For a useful recent study that addresses this very issue, see Regev, 'The "Pop-Rockization" of Popular Music' .

5 This seeming lack of attention given by popular music scholars to issues of form and design in non-expansive pop-rock pieces is addressed by Walter Everett in his 'Confessions from Blueberry Hell'.

6 The terms 'verse', 'refrain', 'chorus', and 'bridge' are used differently in pop-rock music than they are in popular music from the first half of the twentieth century (for an overview of the use of these formal terms in pre-1950s popular song, see Forte, The American Popular Ballad, 36-41. I adhere to the later rock usages, which Walter Everett, in his The Beatles as Musicians, has neatly summarized as follows (315-19):

Verse: a song's section equivalent to the stanza, usually placed directly after any introduction, that nearly always appears with two or three (or, rarely, more) different sets of lyrics, but in rare . . cases . . has one set only.

Refrain: an optional final line of a song's verse, consisting of a lyric, usually containing the title, that does not vary from verse to verse.

Chorus: a song's section ... usually appearing in the song's interior, with lyrics that remain constant with each hearing. If there is no refrain, the chorus is the container of the song's title.

Bridge: a song's contrasting middle section [sometimes called the 'middle-eight', regardless of the number of actual bars], often beginning in an area other than tonic and usually leading to a dominant retransition.

To these I add my own definitions for 'riff' and 'groove', both of which have become important (though far less concrete) terms within the parlance of pop-rock analysis:

Riff: a distinctive melodic/rhythmic idea - usually longer than a motive but not large enough to constitute a full phrase - which is frequently (but not always) sounded over and over again in the manner of an ostinato.

Groove: the tapestry of riffs - usually played by the drums, bass, rhythm guitar and/or keyboard in some combination - that work together to create the distinctive rhythmic/harmonic backdrop which identifies a song. 
It is necessary first to consider briefly some important milestones in the history of recording technology that directly contributed to - if not facilitated - the emergence of accumulative and cumulative forms in pop and rock. I shall use the work of the Beatles, likely familiar to most readers, as an initial point of reference. ${ }^{7}$ As is well known, almost all of the Beatles' songs were produced at what is no doubt the most famous recording facility in the world, EMI's Abbey Road studios in central London (forever immortalized in the Beatles album of the same name). ${ }^{8}$ The first four Beatles singles ('Love me do', 'Please please me', 'From me to you', and 'She loves you') and all the songs on their first LP Please Please Me (March 1963) were recorded the 'old fashioned way' in twin-track mono, as had been the norm for decades, with the vocals on one track and all the backing instruments on the other. Their first taste of four-track recording - which became the industry standard for most of the remaining 1960s - was with 'I want to hold your hand' in October 1963. Looking back from the perspective of today's digital age, where multitracking has become virtually limitless, it seems all the more remarkable that the majority of the Beatles' recordings - including the complex songs from Revolver onwards - were produced using only four-track equipment. EMI had installed eight-track machines and boards at Abbey Road by January 1969, but the Beatles used remote four-track machines for the infamous Let It Be sessions on the rooftop of Apple studios later that same month, and so the first and only Beatles album to be recorded entirely using eight-track equipment was their swansong Abbey Road. ${ }^{9}$

From 1969 to the mid-1970s, advances in recording technology proceeded at an even more rapid pace. Pink Floyd guitarist David Gilmour recalls a discussion at Abbey Road studios that took place prior to the aforementioned installation of the eight-track machines:

I said that they should ignore eight track altogether and switch from four track to 16 track; doing that would save them money and put them in front of most of the other studios. But the Abbey Road people urged that 16 track would never catch on and the jump to eight track was a big enough risk. So they changed to eight track and what happened? A year later they changed it all again . . . this time to 16 track. ${ }^{10}$

7 For a fuller account of the history of multitrack recording than the thumbnail sketch I provide below, see Zak, The Poetics of Rock, 10-17; see also Théberge, "'Plugged in"'. On the Beatles specifically, see Everett, The Beatles as Musicians.

8 EMI officially opened their recording facilities at No. 3 Abbey Road, in St John's Wood, London, on 12 November 1931, with the studio's first ever session being a recording by Sir Edward Elgar conducting the London Symphony Orchestra in a performance of his own Falstaff suite. For a fascinating account of the studio's history through the early 1980s, see Southall, Abbey Road.

9 Overdubbing had been an integral part of the process of making records almost from the very beginning, but the idea of introducing parts in multiple layers under the strictest control was only fully realized with the widespread dissemination of eight-track machines or larger in the late 1960s and early 1970s. The American electric guitar pioneer Les Paul actually had an eight-track machine built for him by Ampex as early as 1957 to accommodate his desire for additional tracks in composing layered recordings, and yet, as Zak reminds us, 'during the first decade of its existence, the possibilities of multitrack recording remained mostly unexplored' (The Poetics of Rock, 15).

I should also point out that stereo records were still considered something of a novelty in the 1960s (much as CDs were when they were first introduced in 1983); the Beatles' LPs were released in both mono and stereo versions, but the first Beatles single to be released in stereo was 'Get back' in April 1969 (very few stereo singles appeared before that year).

10 Quoted in Southall, Abbey Road, 113. 
In fact, the demand for additional tracks was such that sixteen-track was superseded by twenty-four-track at most studios by the mid-1970s. It goes without saying that this sudden increase in the number of available tracks had a profound impact not just on the way pop and rock songs were recorded, but also the compositional process itself. Sixteen- and twentyfour-track recording provided pop-rock composers with greater opportunities for multiple overdubs and layering parts than ever before. A famous example illustrating the new-found possibilities offered by multitrack recording during this period is the 'operatic' middle section of Queen's number one hit 'Bohemian rhapsody' (1975), in which the effect of a huge choir was achieved by Freddie Mercury, Brian May, and Roger Taylor each overdubbing their respective vocal parts dozens of times. ${ }^{11}$ Given that a crucial feature of accumulative and cumulative forms is the ability to introduce parts in multiple layers (an effect somewhat similar to the 'terraced instrumentation' that is characteristic of many Baroque orchestral pieces), it is no accident that these forms become especially rampant in pop and rock compositions beginning in the early 1970 s. ${ }^{12}$

I shall continue this historical sketch a little later, but for now let us proceed with the analysis of some specific tracks, though not necessarily in chronological order. A random sampling from the albums on Billboard's Top 200 will likely confirm that many current pop-rock songs feature at some point on their musical surface a cumulative process of textural growth: various interlocking riffs - such as drum rhythm, bass line, and guitar vamp

11 Needless to say, this massive choral arrangement was impossible to reproduce live; for live performances, Queen would simply stop the song at that point and play a tape of the studio recording. 'Bohemian rhapsody' reigned at number one on the British charts for a remarkable nine weeks from late 1975 to early 1976. It had been (and continues to be) a long-standing tradition on the weekly British television show Top of the Pops for the artist at number one to perform his or her song live (or, until the late 1980s, lip-synching) in the studio at the end of the programme. Queen were touring at the time and found appearing on Top of the Pops to be too inconvenient, so they created a videotaped promotional film for the song to be played in their absence - a clip which is often cited as the first 'music video' in the modern sense (although, in fact, the Beatles were making promo films for their songs to substitute for live appearances a full decade before); see Goodwin, Dancing in the Distraction Factory, 94-5. 'Bohemian rhapsody' captured the hearts of a whole new generation of fans when it was used in the soundtrack for the 1992 comedy film Wayne's World (no one who has seen this film can forget the scene where Wayne announces to his buddies as he inserts a tape into his Plymouth Pacer's car stereo: 'I think we'll go with a little "Bohemian rhapsody", gentlemen ...'). The re-release was timely, coinciding with lead singer Freddie Mercury's sudden death from an AIDS-related illness on 23 November 1991; the song reached number one (again) in Britain and number two in the US in early 1992.

12 Perhaps the most extreme case of a British pop-rock composer exploiting the new-found possibilities of multitrack recording in the early 1970s is represented by Mike Oldfield's Tubular Bells. Released in May 1973 at the height of progressive rock's 'classic' period, the album - which consisted of just two tracks, 'Tubular bells part 1' and 'Tubular bells part 2' (on sides A and B respectively, each clocking in at around twenty-five minutes) - catapulted the unknown Oldfield to almost overnight success in his native Britain (in the US, success for Oldfield was to come about a year later, and then only when director William Friedkin decided to use a four-minute extract from the opening of 'part 1' as the theme music for his controversial horror movie The Exorcist, which peaked at number seven on Billboard's Hot 100 in early 1974).

The work is almost exclusively instrumental, with Oldfield playing practically all the parts himself on over twenty different instruments, requiring almost a year and upwards of 2,000 overdubs to complete. Each 'part' of Tubular Bells can best be thought of as a series of musical 'episodes', many of which represent self-contained accumulative forms in themselves (such as the opening episode of part 1, forever associated with The Exorcist). For a detailed account of the recording process, see Newman, The Making of Mike Oldfield's Tubular Bells; for a discussion of the album's reception history, see Stump, The Music's All That Matters, 152-6; and for more on Mike Oldfield's compositional method, see Holm-Hudson, '(Re)mixing as (Re)orchestration '. 
- are introduced one by one until the groove is complete, a technique most often employed at the beginning of songs. This technique of building up a groove gradually from its constituent parts is often the defining feature of smaller formal units within larger compositions, and so it seems to merit a descriptor all of its own which I will henceforth refer to as accumulative rather than cumulative, reserving the latter adjective for describing the strategy of complete tracks (although, as we shall discover later, an accumulative process can sometimes span an entire song, resulting in a type of larger cumulative form).

The opening track on Radiohead's 2001 album Amnesiac, 'Packt like sardines in a crushd tin box', is a particularly interesting case in point. ${ }^{13}$ Like many songs with an accumulative beginning, 'Packt like sardines' opens with a repeated riff that spotlights a distinctive and unusual timbre: in this case, a high-pitched metallic percussion instrument (which sounds like it might belong in a gamelan) plays a riff with a highly active surface rhythm, consisting mostly of constant semiquavers within the prevailing 4/4 metre. After eight bars, a muted electronic drum kit pattern is introduced (0:15) which at first seems to lock in a fairly straightforward rock beat, featuring a syncopated bass drum riff and snare drum accents on two and four. Soon, however, the drum pattern becomes erratic - it 'stutters', for lack of a better description - and turns the 4/4 metre around so that what we had previously thought was the downbeat is actually beat three; this all takes place over the span of eleven bars. At $0: 37$, the initial groove of the song is completed with the simultaneous addition of two more layers, both played on an electronic keyboard: a four-bar bass line that begins with a stepwise descent from $\hat{1}$ before circling around to arrive back on $\hat{1}$ in its lower octave, and an upper part that simply tolls the tonic note $\mathrm{D}$ over and over in the manner of an inverted pedal point; both of these parts reinforce the rhythmic accents on beat one and the 'and' of beat two that continue to be emphasized within the constant semiquavers of the 'gamelan' part. The groove having now crystallized, Thom Yorke's vocal enters with the first verse at 0:52. Exactly at the point of the vocal entrance the 'gamelan' part abruptly disappears, only to re-emerge (along with additional timbral layers) twelve bars later at 1:15.

Listening to an accumulative beginning is not unlike assembling the pieces of an aural jigsaw puzzle: only when all the layers of the groove are put together can we understand the complete picture. The Radiohead example exploits a procedure that is characteristic of many accumulative beginnings: here, the addition of each new component seems to be a deliberate attempt to surprise the listener - or, at the very least, to toy with the listener's expectations - so that when the groove ultimately does crystallize it sounds as if it has 'emerged' out of a state of rhythmic, metric, and/or tonal confusion. ${ }^{14}$ I must confess that I deliberately did not provide

13 Amnesiac débuted in the number two position on Billboard's Top 200 the week ending 16 June 2001. With their penchant for innovative formal structures and unique sonic landscapes, Radiohead have been branded by some critics as a 'progressive' rock group for the new millennium, although I should say that their music sounds very different from that of the classic prog groups of the 1970s. It is not surprising then that Radiohead's music has begun to attract the attention of music theorists: see, for example, Hubbs, 'The Imagination of Pop-Rock Criticism', 15-19, which offers a close analysis of 'Exit music (for a film)' from their 1997 album OK Computer, and Tatom, 'How to Disappear Completely'.

14 Such accumulative beginnings have become a defining feature of Radiohead's style, as their most recent album Hail to the Thief (released June 2003) confirms (listen especially to the beginnings of 'Sit down. Stand up' and 'The gloaming'). 
a transcription of the opening of 'Packt like sardines' in order to demonstrate just how difficult it is to describe such a complex musical process precisely without the aid of a notated example; all but one of my remaining analyses are accompanied by detailed transcriptions. ${ }^{15}$

The idea of introducing parts layer by layer at the beginning of a song has long been a standard arranging technique in rock (for a very famous example, we need think no further than the signature opening to Deep Purple's 1972 classic 'Smoke on the water'). Yet with the rise of synthesizers, sequencers, and (a little later) drum machines in the 1970s and early 1980s, pop-rock composers were able to control the layering process with ever-increasing precision, resulting in accumulative beginnings that are often musically complex and challenging to analyse. Two more examples of songs with an accumulative beginning will serve to illustrate this. Example 1 shows the opening of the instrumental title track from the Alan Parsons Project's 1977 album I Robot (the transcription is from the onset of the song proper at 1:40, omitting the extended held $\mathrm{C}$ minor tonic chord of the introduction). ${ }^{16}$ As I have illustrated on the top system, each of the first three layers of the groove is introduced into the texture by way of a gradual 'fade-in' - an effect that can be properly achieved only in the recording studio. Like Radiohead's 'Packt like sardines', the opening riff is immediately

15 As with the musicians themselves, many scholars of popular music are quite content to dispense with 'scored objects' (to use Richard Middleton's words) altogether, and I certainly agree that many of pop and rock's most interesting features (timbre and vocal inflection, for example) are almost impossible to convey using conventional notation (see Middleton, 'Introduction: Locating the Popular Music Text', in Reading Pop, 6). Yet it is difficult to discuss other equally important details of this music (form and harmony, for example) without the aid of some kind of graphic representation. For an engaging study of the pros and cons of using transcriptions in popular music analysis see Winkler, 'Writing Ghost Notes'; see also Brackett, Interpreting Popular Music, 27-9; and Everett, 'Confessions from Blueberry Hell', passim.

The music examples in this article represent my own transcriptions of passages from the original studio recordings, which I am considering the Urtexte for these compositions (for an extended defence of this position, see my 'British Pop-Rock Music in the Post-Beatles Era' (PhD dissertation, Yale University, 2001), 3-6). Some excerpts I have rendered more or less in full, while others have been condensed or otherwise simplified, with instruments intentionally omitted at times for the sake of clarity. My goal for the most part has been to reproduce the vocal line as accurately as is practical, while condensing the other parts into a manageable short score. With the exception of the guitar and bass guitar, which sound an octave lower than written, all instruments are notated as they sound. Bar numbers are provided for ease of reference within individual examples. Markers in minutes and seconds (e.g., 4:24), corresponding to the timings programmed into CDs, are used to indicate exactly where specific points in the music occur. Careted arabic numerals refer to scale degrees, and I have used Roman numerals (case-sensitive with accompanying superscripts, so as to indicate chord quality more precisely), figured-bass symbols, and (in one instance) pitch-class set names where I felt they were pertinent to my discussion of the harmonic language of a particular excerpt.

16 With its title taken from Isaac Asimov's 1950 collection of science fiction short stories of the same name, I Robot was one of several concept albums in the late 1970s to explore the theme of the mechanizing effect that technology has had upon society. Among other noteworthy examples of this are Kraftwerk's The Man Machine (1978) and [the] Buggles' The Age of Plastic (1979), both albums which, not surprisingly, are dominated by the sound of synthesizers, drum machines, and other electronic gadgets.

The Alan Parsons Project was not a conventional 'group', but rather an assemblage of various studio musicians led by Alan Parsons and lyricist/manager Eric Woolfson as a vehicle for recording their songs (the personnel on each album would typically rotate from one song to the next). Before forming the Project, Parsons had enjoyed a successful career as an engineer and producer for EMI's Abbey Road studios since the late 1960s: he served as an assistant engineer on the Beatles' Abbey Road album, yet he is probably best known for his work on Pink Floyd's classic prog album The Dark Side of the Moon (1973). An informative account of the genesis of much of the Project's material, including I Robot, can be found in the liner notes to The Complete Audio Guide to the Alan Parsons Project, a 'DJ only - not for sale' boxed set of LPs issued by Arista in the early 1980s (the liner notes can be found on the Web at the following address: < http://www.roadkill.com/APP/discography/AudioGuide >). 
striking and rhythmically very active: a short synthesizer motive featuring a dirty 'sawtooth' timbre, comprising a series of seven pitches mostly in semiquavers, is looped over and over again using an electronic sequencer. The riff begins with a syncopation of two semiquavers tied across the barline, and yet when this riff sounds first in isolation most ears would likely perceive it as beginning on the downbeat, as I have illustrated in the alternative notation (in parentheses) below the staff. To complicate the issue further, after six bars a second layer is faded in to the mix: a repeated synthesizer riff that is an almost exact duplication of the opening, the only difference being that this second layer (what I have called the 'echo synth') is staggered so as to sound precisely one quaver behind the first. What results is an effect not unlike that of Steve Reich's 'phase-shifting' pieces (e.g., Piano Phase of 1967), in which two identical ostinato parts slowly diverge from one another as one of the parts gradually speeds up. In 'I Robot', the two parts remain at the same speed, and yet the 'micro-canon' at the quaver resembles the effect achieved at the moment when the 'speeding-up' part in a phase-shifting piece overtakes the rhythmically steady part by a given rhythmic increment. ${ }^{17}$

After about two bars of the two synth parts sounding together, a third layer - the drum kit - is gradually faded in. This drum layer forges an additional similarity with 'Packt Like Sardines' in that it also features a syncopated bass drum pattern alongside the standard rock cliché of snare hits on beats two and four (the so-called 'backbeat') with steady quavers in the hi-hat. While this solid rock backbeat removes the sense of metric ambiguity conveyed by the initial syncopation in the repeated synth riff, the listener is still made to feel uncertain as to where beats one and beat three fall within the 4/4 bar: as I have shown in Example 1, each half of the repeated one-bar bass drum riff 'reverses' after three bars so that what had previously occupied the second half of the bar now occupies the first, and vice versa (an effect that must have been carefully calculated). It is only when the fourth layer - the electric bass - enters at full volume (the bass is not faded in to the mix, as were the three previous layers) that our aural game of 'hunt the downbeat' is finally over, as the bass plays its own one-bar repeated riff, which squarely accents the tonic note $\mathrm{C}$ on the first beat of every bar (prefaced each time by a quick chromatic walk-up).

17 For a probing analytical study of such pieces, see Cohn, 'Transpositional Combination of Beat-Class Sets'. The structural similarities of minimalist art music to many of the accumulative and cumulative formal processes in pop and rock discussed in this article can hardly be overstated, and would themselves merit an extended study that space does not permit here. I should note, however, that minimalist composers have had a concrete influence on certain British pop-rock musicians. Probably the clearest case of this is represented by the work of the Who's guitarist and main composer Pete Townshend. Having heard the minimalist music of the American composer Terry Riley in the late 1960s, Townshend sought to create similar textures of his own with the aid of synthesizers, tape loops, and sequencers, a famous example being the accumulative beginning to 'Baba O'Riley' - the title of which is a deliberate nod to Riley's name - from the groundbreaking 1971 album Who's Next (the opening riff to the song was created using the 'marimba repeat' function on a 1968 Lowrey Berkshire Deluxe TBO-1 home organ, recorded at half speed and then doubled in tempo for the final mix to achieve its uniquely frenzied effect).

The addition of synthesizers to Townshend's songs markedly transformed the sound of the Who from that of a 'power trio with vocals' (featuring just guitar, bass, and drums) to what often sounded like a progressive rock group, the main difference being that Who songs were less expansive and the riffs leaner and simpler than that of their prog counterparts. Songs featuring a sequenced, arpeggiated keyboard beginning became a Townshend trademark, as exemplified by the later Who singles 'Who are you' (1978) and 'You better you bet' (1981), and his solo hit 'Let my love open the door' (1980). 


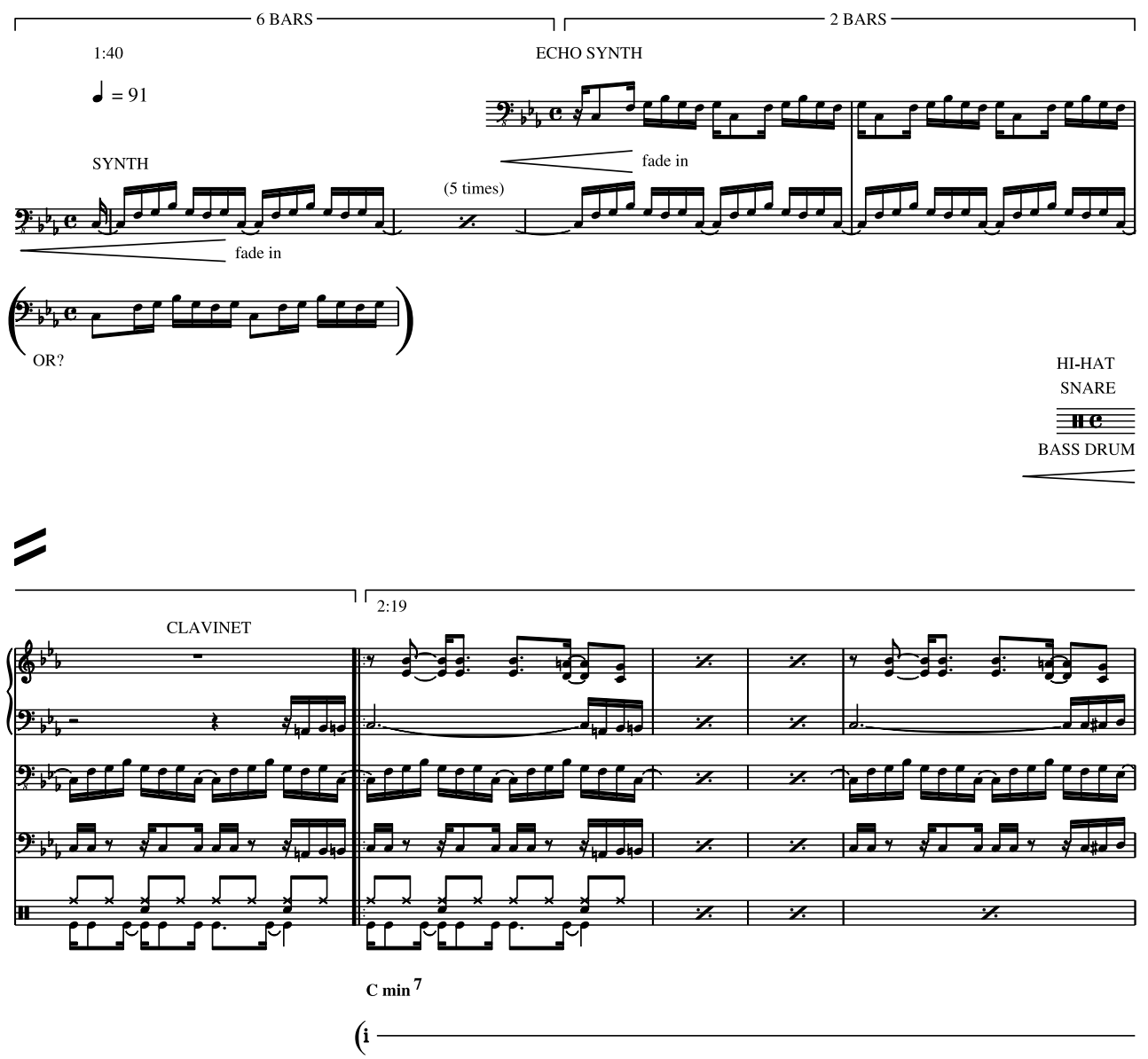

Example 1 The Alan Parsons Project, 'I Robot' (1977), from the beginning of the song proper.

It was mentioned earlier that the compositional strategy of accumulative beginnings often seems to be one of deliberately confusing the listener. This is certainly true of the opening of 'I Robot': not only is the location of the downbeat called into question, but also the textural 'blocks' - marked by the entrance of each new layer - are erratic with respect to their lengths. I have indicated this in Example 1 by bracketing each of these blocks above the staves, revealing an irregular hypermetre of six bars, two bars, three bars, and four bars respectively. With the addition at 2:19 of the fifth and final layer - the Clavinet - the groove for the first time crystallizes into the repeated eight-bar vamp that underscores the majority of the remainder of the track. ${ }^{18}$

18 Introduced by Hohner in the mid-1960s, the Clavinet soon became a staple within the ever-growing arsenal of pop and rock keyboards; see Vail, Vintage Synthesizers. With its brittle tone and lack of sustaining power, the timbre of a Clavinet - literally, an electric clavichord - could perhaps be thought of as resembling that of an amplified and distorted harpsichord. Soul and funk musicians on both sides of the Atlantic have been especially fond of the instrument; one need only listen to any Stevie Wonder album from the 1970s to hear the Clavinet in all its glory. (I should note that jerky, syncopated rhythms and sparse chord voicings in open fifths, such as those featured in the 'I Robot' vamp, are entirely idiomatic to the instrument). 


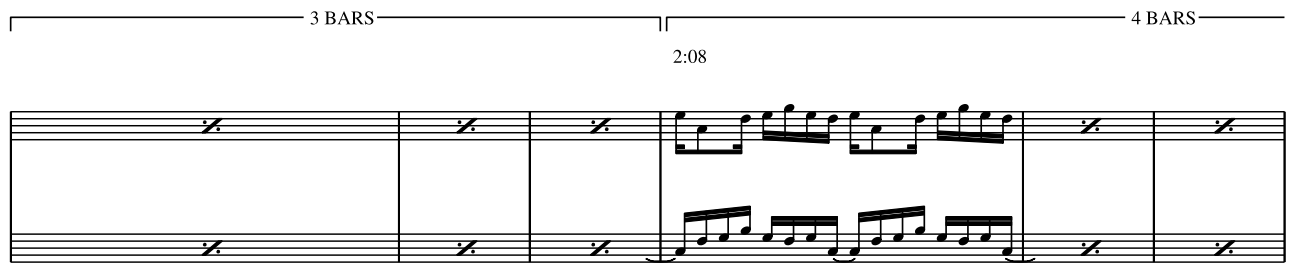

ELECTRIC BASS
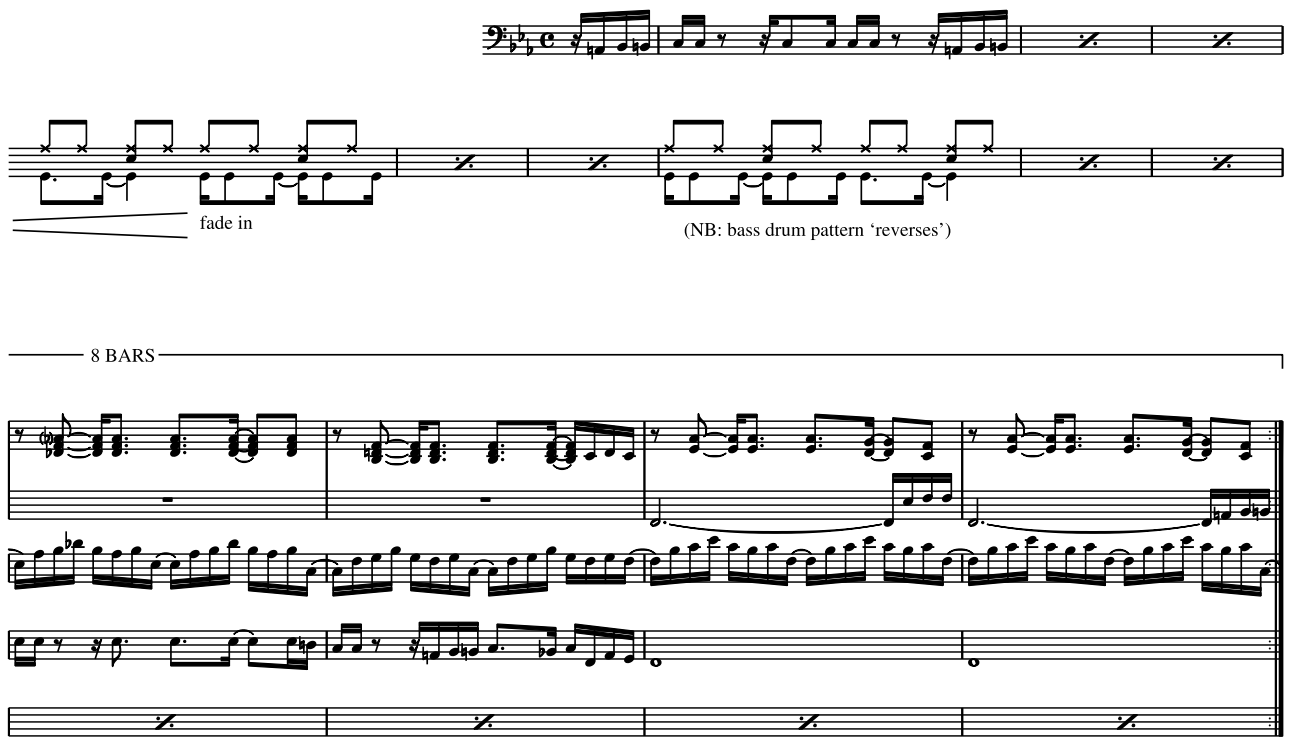

$\overbrace{\text { iii }(!)}^{\mathrm{Db}} \mathrm{Eb}_{\text {bass }}^{\mathrm{Bb}} \mathrm{C}_{\mathrm{C}}$ bass

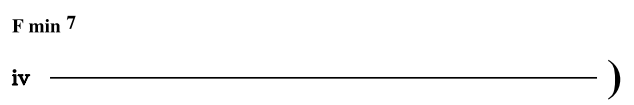

Example 1 continued

Up to this point, the emerging groove has remained static on the tonic harmony, but now the groove passes through a clearly defined eight-bar progression. I have analysed this progression below the staves in two ways, first using conventional 'lead sheet' chord labels, and second using Roman numerals to indicate the chord functions with respect to the prevailing key of $\mathrm{C}$ minor. The first harmonic move is quite unusual: after standing on the tonic for four bars, the harmony shifts by way of a chromatic third relation to the minor mediant (iii) in bar five, swerves back to the tonic in bar six, and then moves to the subdominant for bars seven and eight, after which the whole progression begins anew (note the complete avoidance of the dominant, a feature which is often characteristic of modal rock harmony). ${ }^{19}$ With each of these chord changes, the ostinato synth riff (now shown on the middle staff) is transposed exactly (having presumably fulfilled its purpose, the 'echo synth' drops out of the texture when the Clavinet enters). The other parts, however, do not

19 For two representative studies on the use of modal harmony in rock music, see Moore, 'The So-called "Flattened Seventh" in Rock'; and Burns, 'Analytic Methodologies'. 
transpose exactly with every chord change: for example, the right hand of the Clavinet part establishes in the first four bars a repeated, syncopated one-bar jabbing motive in open parallel fifths (note the prominent use of dorian $\$ \hat{6}$ ), which 'inverts' to become parallel fourths in bars 7 and 8; but in bars 5 and 6, the Clavinet deviates from this pattern by playing full triads in the right hand. Taken along with the bass pitches, these triads create what are often described in the parlance of jazz harmony as 'polychords' - in this case, $\mathrm{D} b$ and $\mathrm{B} b$ major triads respectively sound above the pitches $\mathrm{E} b$ and $\mathrm{C}$ in the bass. Such chords are certainly frequent in jazz, and yet this particular polychordal voicing is straight out of the harmonic language of 1970s rock. Although the chords here do not have dominant function, they conform exactly to the distinctive voicing of the so-called 'rock dominant', a polychord which can best be thought of as a close-position IV triad in the right hand sounding above $\hat{5}$ in the bass, hence conflating subdominant and dominant functions. ${ }^{20}$ One additional detail worth mentioning about this composite texture is that the left hand of the Clavinet part seems deliberately to drop out in bb. 5-6, presumably so as not to clash with the active electric bass part during these bars. ${ }^{21}$

Before we move on to the next example, let us return to our historical sketch for a moment. So far we have seen how the rapid advances in multitrack recording, along with the rise of synthesizers and sequencers, had a profound effect on the types of pieces that pop and rock musicians were able to compose during the 1970s. From 1979 through the early 1980s, without a doubt the most important new technological development in this respect was the sudden availability of several powerful and relatively affordable drum machines, such as the Linn 9000 and the Roland TR-808. Whereas earlier drum machines had sounded tinny and unrealistic, many of these later machines exploited the brand new technology of digital sampling, allowing for the first time the playback of sounds captured digitally from actual percussion instruments or other 'real-life' sources. ${ }^{22}$

The rise of the drum machine caused nothing less than a revolution within British popular music in the wake of punk rock: if you owned a few keyboards and a drum machine, you could form a pop group without necessarily any of its members being able to play guitar, bass, or drums (such as was the case with many of the so-called 'New Romantic' groups of the early

20 Because the rock dominant is somewhat difficult to voice on the guitar, it seems to be more characteristic within the harmonic language of keyboard-based pop and rock songs. Two obvious examples are 10cc's 'I'm not in love' (1975) and Paul McCartney's Wings song 'With a little luck' (1978), each of which opens with a rock dominant (played on electric piano) as its signature hook. The chord likely has varied origins, both in gospel piano playing (indeed, the chord is as prevalent in soul music as it is in rock) and in American popular song from the first half of the twentieth century, where often at cadences one finds the melody moving directly to $\hat{1}$, without a preceding $\hat{2}$ or other note that would support a pure V, as in the final cadence of Cole Porter's 'Night and day' (1932). A true rock dominant, with a IV triad in the right hand over $\hat{5}$ in the bass, can be found at the final cadence of Rodgers and Hart's 1938 song 'Who are you?' (not to be confused with the aforementioned Who song of the same name).

21 Although not shown in Example 1, the accumulative layering process actually keeps going on the first repetition of the eight-bar vamp (2:40 ff.), as a funky electric guitar part is added to the texture.

22 For detailed information on the Linn 9000, Roland TR-808, and the myriad other drum machines that were introduced during the early 1980s, visit 'The Drum Machine Museum' at <www.drummachinemuseum.com>; see also Théberge, " "Plugged in"'. 
1980s). ${ }^{23}$ Indeed, some punk groups actually went so far as to shed their guitars (along with their typical, angry, distorted power chords) and to reinvent themselves in light of the new technology - spawning a whole new style of music, appropriately named 'techno'. One of the most important and influential of these early techno groups was the Manchester quartet New Order. In Example 2 I have transcribed the opening section of their breakthrough single 'Blue Monday' (1983) - which, as we shall see, features another accumulative beginning. ${ }^{24}$

The song opens with its signature two-bar bass drum riff, a riff whose rapid-fire semiquavers could only have been produced by a drum machine (in this case, an Oberheim DMX). After four repetitions of this motive, a synthesizer part in the middle register - what I call the 'delay synth' - is gradually faded into the mix. As I have shown in parentheses below the staff, the alternating quaver and crotchet feel of this added synth part actually conveys a $6 / 8$ metre, thus creating a metric dissonance against the rigid 4/4 pulse of the bass drum ostinato. The texture of what I have labelled Groove 1 is completed eight bars later with the sudden forte entrance of three more components. At the forefront of the texture is a bass synthesizer part (sequenced using a Moog Source) in constant bouncing octaves, whose pitch structure $-\mathrm{F}-\mathrm{C} / \mathrm{D} / \mathrm{G}-\mathrm{C} / \mathrm{D}$ - had been foreshadowed in the delay synth part that continues to sound above it. And two instruments have been added to flesh out the underlying drum rhythm: offbeat-semiquavers in the hi-hat, and a gated snare drum accenting the backbeat.

Soon after Groove 1 has been fully established, a two-bar drum break abruptly clears the air for a second small accumulative form (labelled Groove 2) to begin. Now the bass synth which had been the final component to enter in Groove 1 - works in tandem with the drum machine to initiate the form (notice that the off-beat semiquavers have now been stripped away in the bass synth and hi-hat parts, and the bass drum has reverted to a simpler 'four-on-the-floor' pattern of constant crotchets). A new series of distinctive timbral layers -

23 Possibly the first recording by a British group to feature a drum machine was Squeeze's début single 'Take me I'm yours', recorded in 1976 and (re-)released in February 1978 (the original January 1977 release was deleted). As Glen Tilbrook explains in the liner notes to Squeeze's 1996 compilation album Excess Moderation: 'we hired lots of synths and a bloke who knew how to work them and pretended to be Kraftwerk'.

Noteworthy among the many recordings by British pop-rock groups in the early 1980s produced using nothing but synthesizers and drum machines are Orchestral Manoeuvres in the Dark's self-titled début album (1980), the Human League's Dare (1981), and Yaz[oo]'s Upstairs at Eric's (1982). Of course, these post-punk groups were not the only ones to experiment with drum machines in an effort to create new sounds. The progressive rock group Genesis, for example, first used a drum machine in tandem with Phil Collins's acoustic drums on their 1980 album Duke; indeed, the 'drum-machine beginning' quickly became a trademark of the new Genesis sound of the 1980s, as exemplified by such songs as 'Me and Sarah Jane' and 'Man on the corner' from Abacab (1981), and the UK top-five single 'Mama' (1983).

24 New Order arose from the ashes of the punk group Joy Division after lead singer Ian Curtis committed suicide on 18 May 1980. The three surviving members - guitarist Bernard Albrecht (who changed his last name to Sumner), bassist Peter Hook, and drummer Stephen Morris - were augmented by Morris's girlfriend Gillian Gilbert on keyboards. While they did not shed their guitars entirely, they wholeheartedly embraced the new synthesizers and drum machines, and were groundbreaking in their experiments with sequencing technology.

Because of its extended length (over seven minutes), 'Blue Monday' was one of the first pop-rock songs in the 1980 s to be released only as a twelve-inch single. While the song initially received limited airplay on mainstream radio stations, it was hugely successful in dance clubs; in fact, 'Blue Monday' still holds the distinction of being the biggest selling twelve-inch single ever in Britain, prompting two later remixes - 'Blue Monday 1988' and 'Blue Monday 1995' - each of which was successful in its own right. The song was revived again in 1999 when the California rapcore band Orgy had their breakthrough hit in the US with a cover of 'Blue Monday'. 
40 Spicer (Ac)cumulative Form in Pop-Rock Music

GROOVE 1

DELAY SYNTH (approximated: rhythmic pattern varies slightly on each repeat)

$\cdot=130$

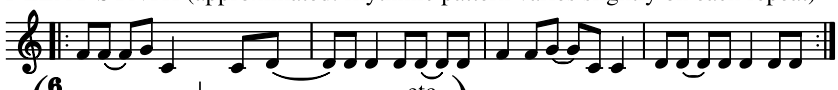

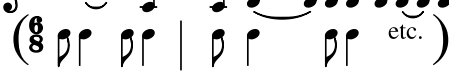

BASS SYNTH

9:

DRUM MACHINE

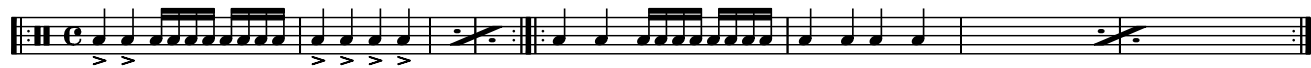

GROOVE 2

BASS

GUITAR

(DRUM BREAK)

BASS SYNTH

$\frac{8}{9}$

$0: 59$

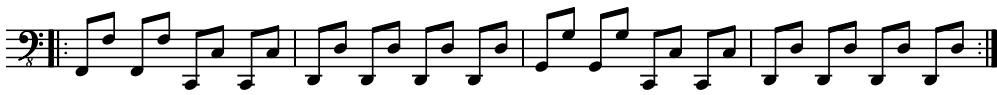

․ $>3272$.

(

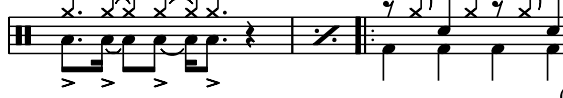

(2nd time begin drum machine effects)

STRING SYNTH 1
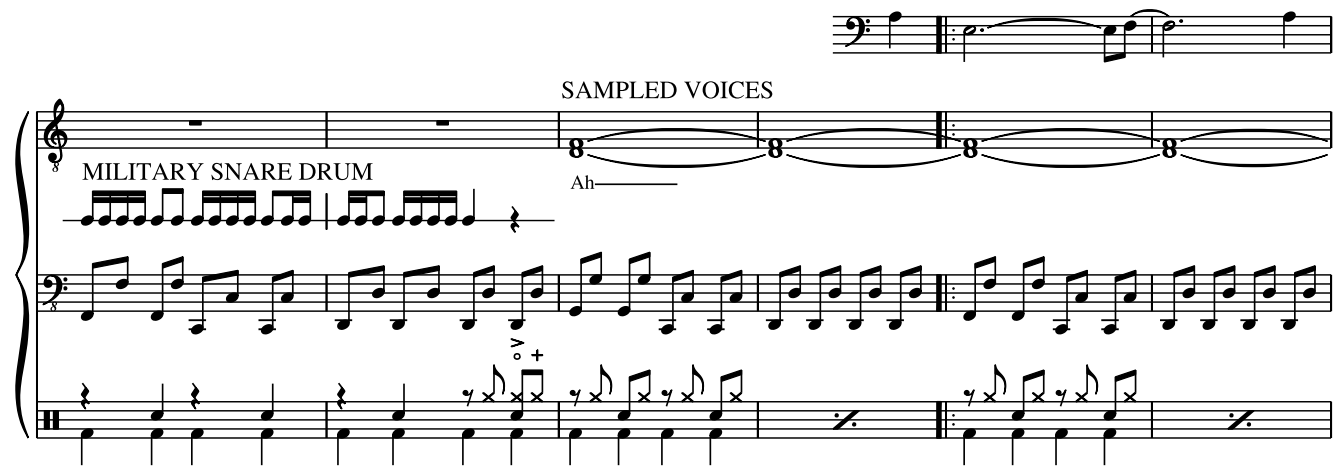

Example 2 New Order, 'Blue Monday' (1983), opening section (before the first vocal entrance). 
Spicer (Ac)cumulative Form in Pop-Rock Music $\mid 41$
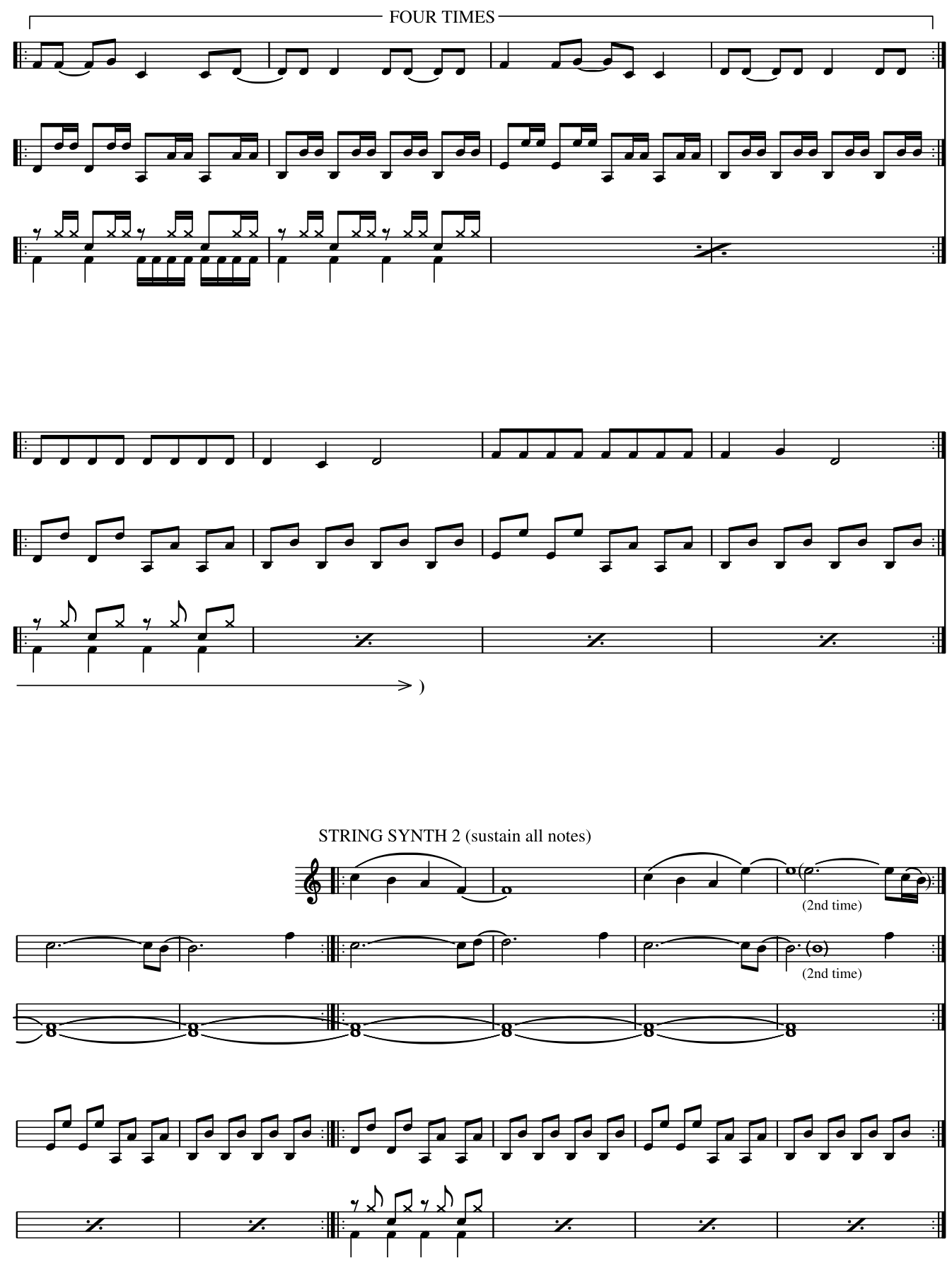

Example 2 continued 
consisting, for the most part, of repeated four-bar patterns (note the bass guitar played in the extreme upper range of the instrument, a Peter Hook trademark) - is introduced above the bass synth ostinato in an ever-thickening texture, so that by the time Groove 2 is complete a considerable registral space has been opened up: from a nadir $\mathrm{C}$ to an apex $\mathrm{e}^{2}$.

In addition to this registral expansion, what might be described as a gradual filling-in of dorian pitch space occurs as each new timbral layer enters. While there is no conventional harmonic progression to speak of in this music, the pull towards D every other bar in the bass clearly establishes this pitch as the modal centre within a dorian framework. With the entrance of the final component - the upper string synth part - all seven pitches of the white-note diatonic collection are made to sound more or less together in one giant sonority. ${ }^{25}$ And, as before, immediately after Groove 2 has been fully established the texture abruptly thins out again, only this time in order to make way for the entrance of the vocal. ${ }^{26}$

Having now focused in some detail on songs with an accumulative beginning, let us consider a case in which an accumulative process takes over as the prevailing compositional strategy for the entire track, creating a larger type of cumulative form: 'Voices inside my head' (1980), one of the lesser-known songs from the post-punk trio The Police. Rather than provide my own transcription, I have chosen to reproduce in Example 3 the published sheet music version. As with most pop-rock sheet music, the notation is overly simplified and woefully inadequate in conveying some of the most interesting subtleties of this music (for example, the intricate rhythmic development of Stewart Copeland's drumming is left out entirely; and, typically, the tempo indication of $d=100$ is omitted). Yet the sheet music rendition does encapsulate nicely the minimalist nature of this track. For one thing, the pitch structure of the song is entirely pentatonic. Secondly, there is no distinction to be made between verse and chorus: the whole song unfolds over a repeated bass and guitar riff, which at first hovers on the pitch $\mathrm{B}$, then slowly gains momentum by expanding to involve the pitches within a fifth above and below this central pitch. Since bassist Sting and guitarist Andy Summers are playing their parts on live instruments rather than relying on sequencers, they are able to incorporate subtle variations into each repetition of their respective riffs. These 'micro-

25 Six of the seven pitches of the collection-D, E, F, A, B, and C-are sustained in the upper three synth parts. This leaves only a missing $G$, which sounds prominently in the bass synth in the third bar of each repeated four-bar segment. While some might find the analogy a bit far-fetched, this process of registral expansion in the service of unfolding a single sonority in 'Blue Monday' reminds me of Wagner's orchestral prelude to Das Rheingold (1857; premièred 1876), which, as most readers will know, is composed mainly of a huge expanding $\mathrm{E} b$ major triad; for a detailed study of this piece, see Darcy, 'Creatio ex nihilo'.

26 This opening strategy - gradually unfolding a big accumulative texture that abruptly thins on the first vocal entrance - has since become a standard blueprint for New Order songs. Compare, for example, 'The perfect kiss' from Low-life (1985), and 'Bizarre love triangle' from Brotherhood (1986).

The music video for 'The perfect kiss', directed by Jonathan Demme (who went on to achieve greater fame with, for example, his 1991 Oscar-winning film The Silence of the Lambs), is fascinating in that it consists of nothing but an intimate, microscopic view of New Order performing the song in real time at the Factory Records studio in Manchester (the video is available on the 1989 compilation Substance). One can watch the accumulative beginning to the song unfold as the camera zooms in on the band members one after another, introducing their respective parts, one by one. 
Spicer (Ac)cumulative Form in Pop-Rock Music $\mid 43$
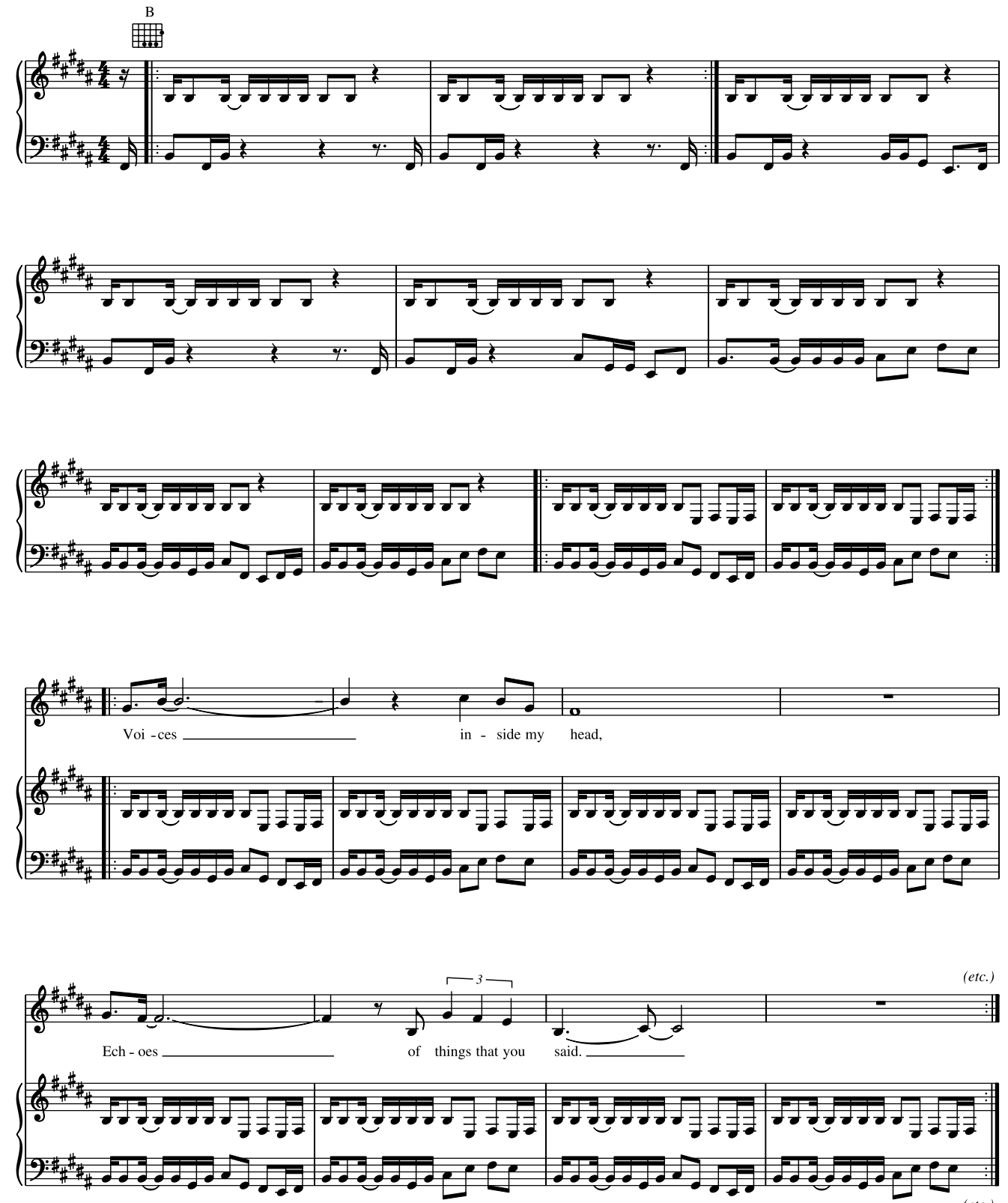

Example 3 The Police, 'Voices inside my head' (1980), sheet music version. Written and composed by Sting. ( 1980 G. M. Sumner. Published by Magnetic Publishing Ltd and administered by EMI Blackwood Music in the USA and Canada. All rights reserved. International copyright secured. Used by permission. 
variations' sustain the listener's interest by allowing for constant change within an otherwise highly repetitive structure. ${ }^{27}$

Well over a minute into the track, the vocals enter as the final component of the texture. The bass and guitar continue to centre on $\mathrm{B}$ as a kind of extended pedal point; however, the vocal tune seems to gravitate much more strongly towards $\mathrm{C} \#$ as its tonal centre, and as a result we begin to hear the prolonged B in the bass below as the subtonic. To my ears at least, the harmonic design of the song as a whole has the effect of a gigantic dominant prolongation that never resolves (with $b$ VII substituting for V, as it frequently does in rock harmony).28 Also noteworthy is the treatment of Sting's vocal, which has been overdubbed with background voices so as to sound the melody at both an octave and two octaves lower, a fairly common technique in pop and rock recordings. Here the multitracked vocals give the singer's persona a kind of 'split personality' in accordance with the message in the lyrics (after all, we are told that there is more than one voice inside the singer's head). ${ }^{29}$ The melody encompasses eight bars and repeats four times, following which - in one last burst of added intensity - the voices begin to shout the syllable 'cha' to reinforce the snare drum accents on the backbeat. ${ }^{30}$

Although the large cumulative form is now complete, the song is not yet over. In an abrupt thinning of the texture - and recalling the opening - the guitar and bass go back to hovering on $\mathrm{B}$, over which a brief coda section emerges featuring fragmentation of the vocal melody and various psychedelic effects. This coda section is reminiscent of so-called 'dub style', a studio technique made popular in 1970s Jamaican reggae music that involves reducing the texture to just one or two parts - usually the drum and bass - and fading the other parts in and out of the mix. ${ }^{31}$

We shall now move back about a decade - to the beginning of the post-Beatles era - to examine the use of cumulative form in a track by the progressive rock group Yes (Example 4). Like many progressive rock pieces, 'I've seen all good people' is a suite, comprising in this case two contrasting movements. The first movement, 'Your move' (composed by lead singer Jon Anderson), is a gentle pastorale that features primarily acoustic instruments, while the second movement, 'All good people' (composed by bassist Chris Squire), is a hard-rocking

27 I believe it was Brian Eno who once said that 'repetition is the most effective means of change'.

28 The dichotomy between $\mathrm{B}$ and $\mathrm{C} \#$ is actually foreshadowed at the opening of the song, where the guitar momentarily plays $\mathrm{C} \#$ before joining the bass on the repeated $\mathrm{B}$.

29 I discuss a similar treatment of Peter Gabriel's voice as heard in the opening section of Genesis's 'Supper's ready' (1972) in my 'Large-Scale Strategy and Compositional Design', 85.

30 Vocal chanting such as this was a hallmark of the Police sound throughout their brief career; the 'cha's in 'Voices inside my head' make specific reference to an identical effect used in the title track from the Police's prior album Reggatta de blanc (1979).

31 For a useful account of the history of dub, see Barrow and Dalton, Reggae: the Rough Guide, 197-228. Along with the Clash (e.g., 1979's London Calling) and the Specials (e.g., 1981's 'Ghost town'), the Police were one of many post-punk groups in Britain to be profoundly influenced by reggae. For a representative survey of some of these groups, see Frith, 'The Coventry Sound - The Specials'; and for a more detailed study of the Police's unique appropriation of the reggae style, see my 'Ghosts in the machine'. 


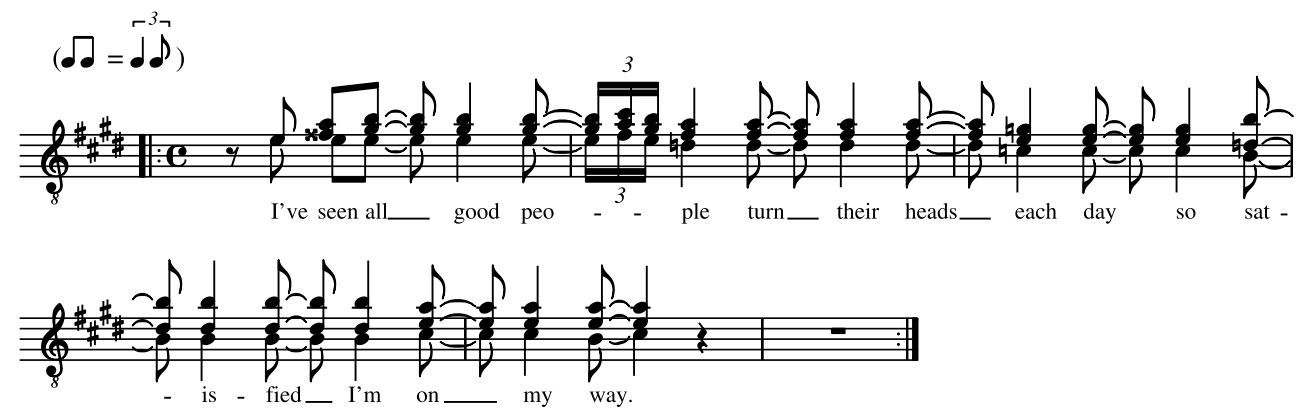

Example 4a Part 2, 'All good people', introductory vocal riff.

Example 4 Yes, 'I've seen all good people' (1971). Includes Jon Anderson, 'Your move', and Chris Squire, 'All good people'). (c) 1971 (renewed) Topographic Music Ltd. All rights administered by WB Music Corp. All rights reserved. Warner Bros. Publications US Inc., Miami, FL 33014. Used by permission.

blues-style shuffle that showcases Steve Howe's virtuoso electric guitar playing. ${ }^{32}$ The movements were originally composed separately, yet it is clear that some collaboration must have taken place - probably in the recording studio - in order to integrate the two movements into a cohesive whole.

As I have shown in Example 4a, the song begins with a repeated three-part vocal riff sounded a cappella. Only later do we discover that this riff is not arbitrary, since it reappears as the vocal chorus that sounds over and over again throughout the second movement. Following a brief interlude played by Steve Howe on a Portuguese twelve-string guitar (not shown in the example), the song proper begins with the entrance of Jon Anderson's vocal (Example 4b). ${ }^{33}$ Similar to what we encountered in the Police's 'Voices Inside My Head', 'Your Move' amounts to one gigantic prolonged harmony: almost the entire movement is cast over an E tonic pedal in the bass, which thuds like a heartbeat at the beginning of every bar. ${ }^{34}$ The song is organized in three verses, each of which is cast in a miniature three-part form (I have labelled these parts $A_{1}, B$, and $A_{2}$ as they occur in the score). The flanking $A$ sections of each verse are built upon a repeated four-bar progression in the guitar, I-ii-iii-ii, while the inner B section - which always sets the lyric ' 'cause it's time, in time ...' - differs from the A sections in that the guitar lingers on the second ii chord for four bars, resulting in an irregular phrase length of seven bars. ${ }^{35}$

32 'I’ve seen all good people' thus employs a 'systematic juxtaposition' of 'acoustic and electric sections', which Edward Macan has identified as a crucial organizational principle for many large-scale progressive rock pieces; see his Rocking the Classics, 43.

33 As Yes expert John Covach informs me, Steve Howe has admitted that for years he mistook this Portuguese twelve-string - which was a gift from his sister, who had brought it back with her from vacation - for an instrument he believed was called a vachalia, and hence it is listed this way on the liner notes to The Yes Album. Howe also used the instrument on 'Wonderous stories', the hit single from the 1977 album Going for the One.

34 For further discussion of the 'pedal-point piece' in progressive rock, see my 'Large-Scale Strategy and Compositional Design in the Early Music of Genesis', 87-9.

35 The progression I-ii-iii-ii as a tonic expansion is an old r\&b formula (e.g., Barbara Mason's 'Yes I'm ready', 1965). Variants of the progression can be found in other styles, such as in the main vamp of Van Morrison's 1970 lounge-rock classic 'Moondance', which uses the dorian i-ii-III-ii (all seventh chords). 
46 Spicer (Ac)cumulative Form in Pop-Rock Music
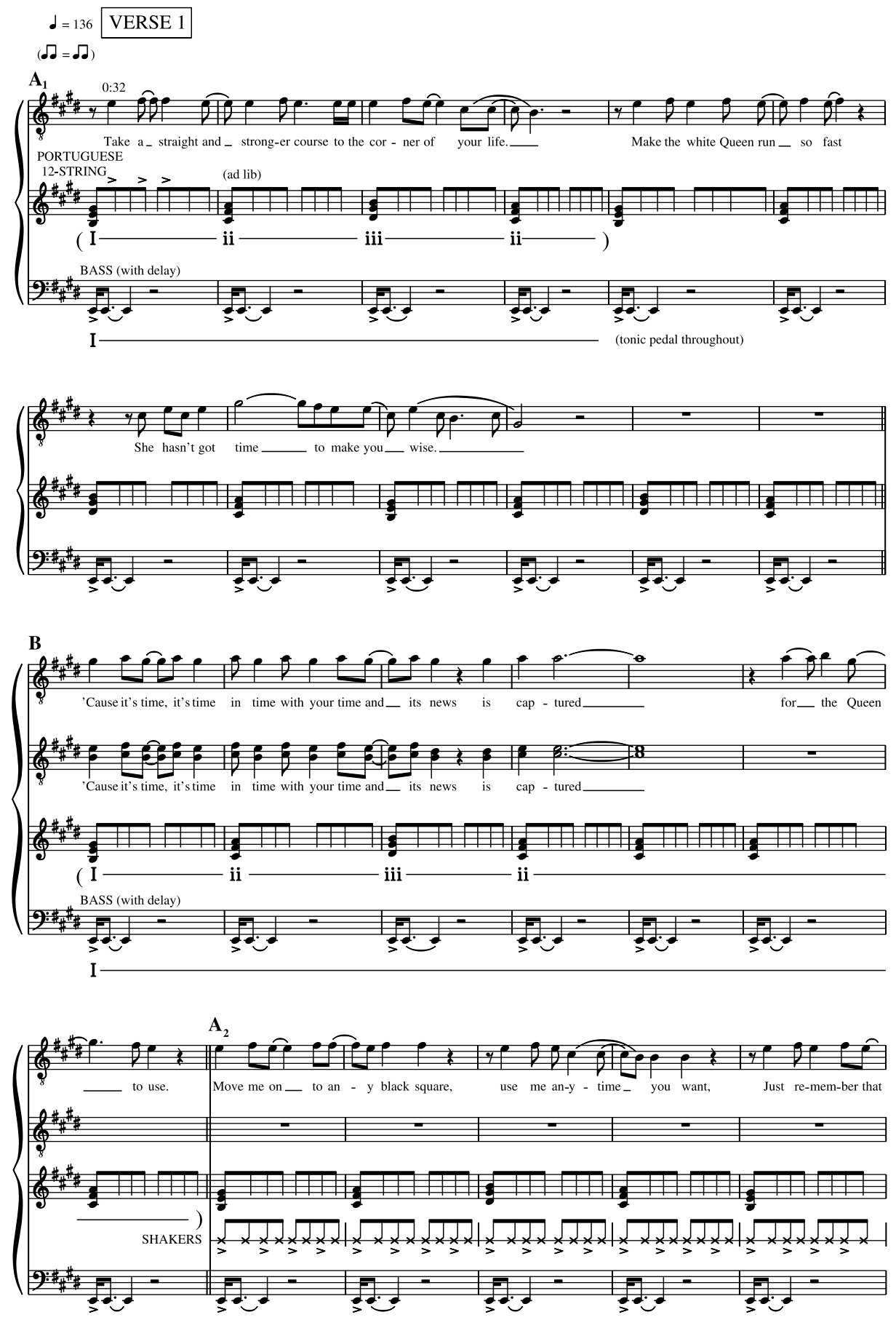

Example 4b Part 1, 'Your move' (Jon Anderson), from the opening (guitar introduction omitted). 

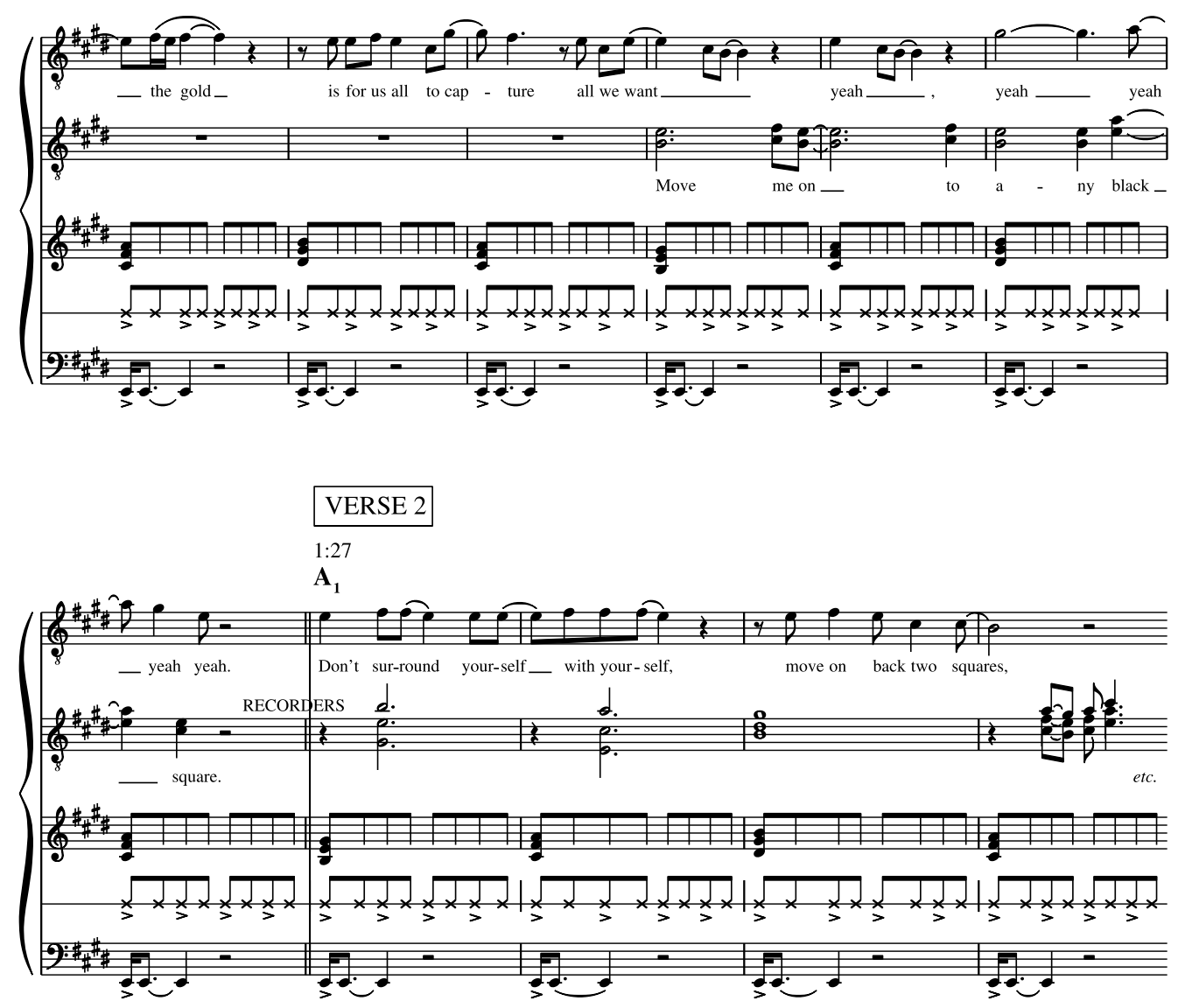

Example $4 \mathrm{~b}$ continued

Over the course of the three verses of 'Your move' new parts are layered in one by one, unfolding a large-scale cumulative form for the movement as a whole. Of these added parts, the consort of three recorders that enters at the beginning of the second verse is particularly beautiful (one recalls the similar use of recorders in the Rolling Stones' 'Ruby Tuesday' (1967) and Led Zeppelin's 'Stairway to heaven' (1971)). The song also features Yes's trademark sophisticated use of background vocals: Chris Squire and Steve Howe join Jon Anderson's lead vocal in three-part harmony during the B sections, but also introduce entirely new counterpoints to the vocal melody during the later A sections. The icing on the cake is Tony Kaye's pipe organ, which enters dramatically at the end of the third verse (Example 4c) and has the effect of breaking the tonic pedal with a bass that moves mainly by step. ${ }^{36}$ Notice also

36 In songs where an accumulative process gradually unfolds over the course of the entire track, it often seems to be the case - as with the entrance of the organ in 'Your move' - that the addition of the final layer is consciously 'saved' by the composer so as to achieve a big emotional climax when it ultimately does appear. Two of my favourite examples of this are both by ex-members of Genesis. In Peter Gabriel's first solo hit, 'Solsbury Hill' (1977) - the song that chronicles his anguish over leaving Genesis in 1975 - the sudden forte entrance of a downward-sliding electric guitar power chord (prior to this in the song we had heard only acoustic guitars) adds special dramatic weight to the end of the final refrain. And in Phil Collins's 1981 solo breakthrough 'In the air tonight' - one of the most famous early 1980s 

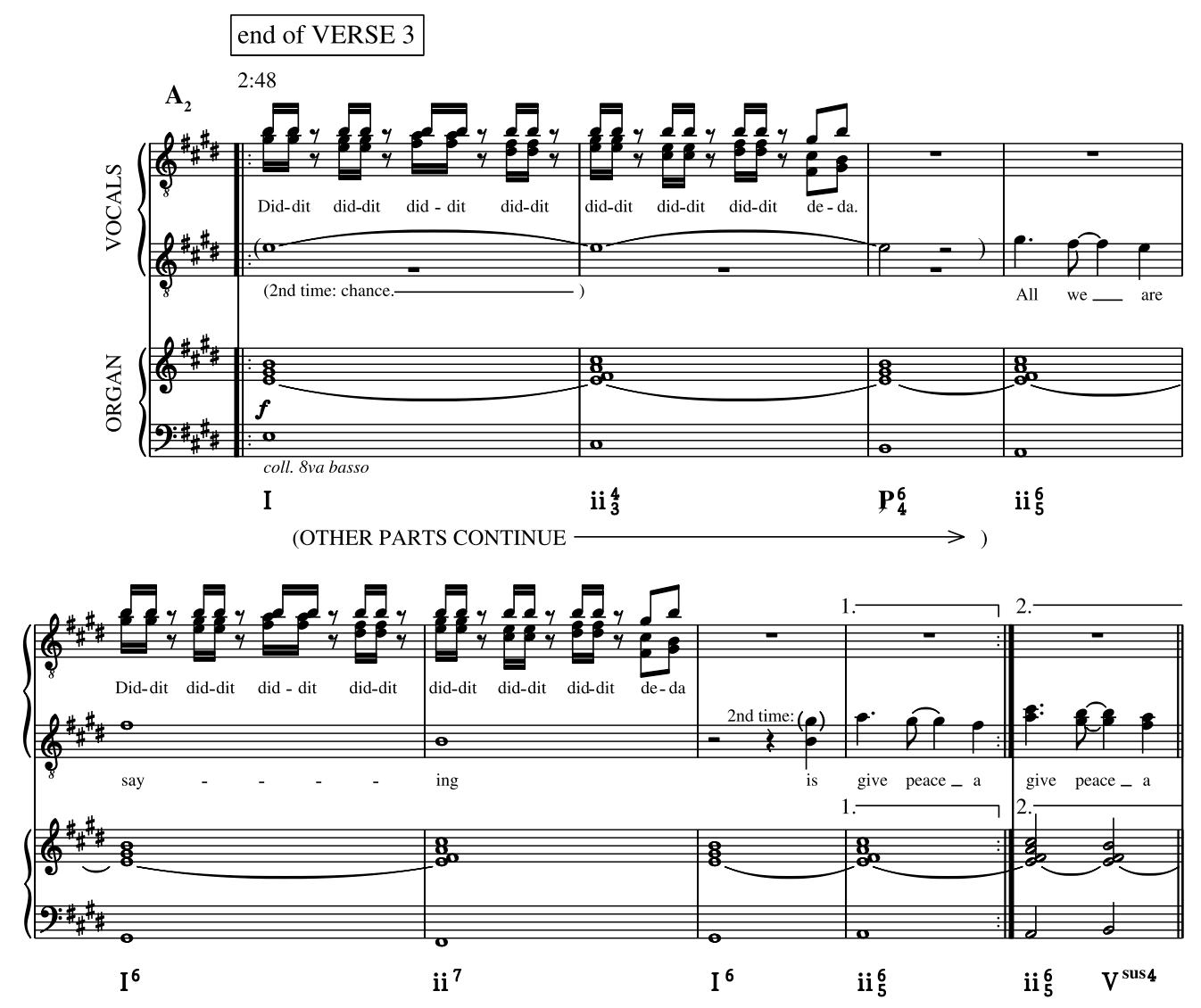

3:17

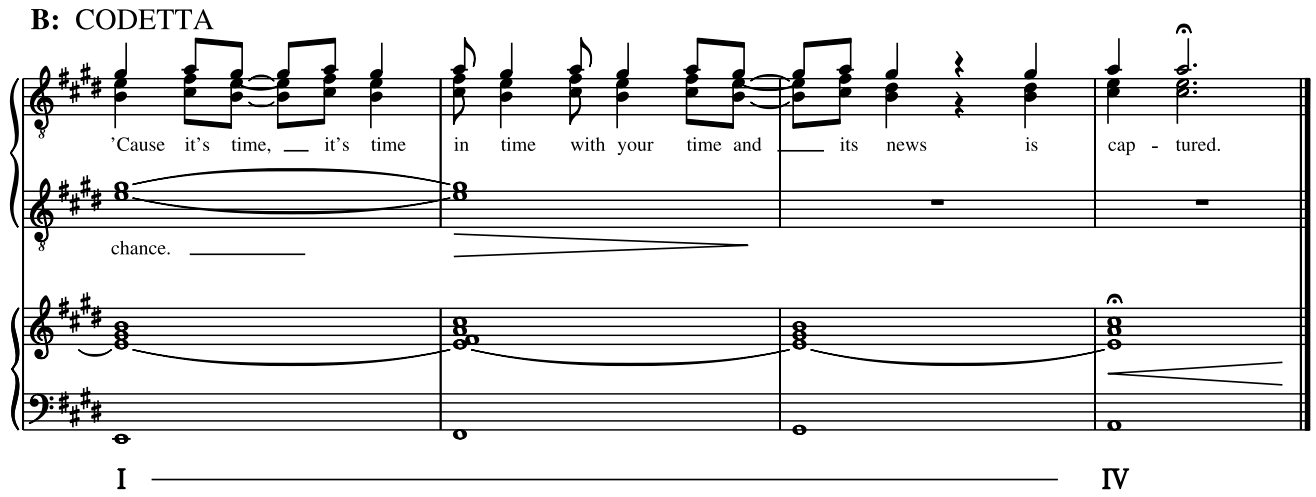

Example 4c 'Your move', from the end of verse 3.

the strategic intertextual reference to John Lennon's 1969 Plastic Ono Band song 'Give peace a chance', which is woven into the contrapuntal fabric during the final verse in an effect not

songs to feature a drum-machine beginning - the gigantic entrance of a trademark Collins descending tom-tom riff (prior to this in the song we had heard no acoustic drums, only the drum machine) bumps up the level of emotional intensity several notches at the onset of the final chorus. 
unlike that of a Baroque quodlibet ${ }^{37}$ A brief codetta - featuring a fragment of the B material - closes the movement, rising to a spectacular cadence on the subdominant.

I mentioned previously that there must have been some collaboration between the two composers in order to make their respective movements work together logically as one cohesive piece. The compositional strategy for the closing section of the second movement, 'All good people' - which also functions as the closing section of the track as a whole - seems to confirm this (Example 4d). Just prior to this closing section, the pipe organ - which it will be recalled was the final component of the accumulative texture to enter in 'Your move' - is gradually faded into the mix, while the other parts are gradually faded out. What we are left with is a massive chordal setting of the vocal chorus accompanied by just the organ and bass. Not only does this prominent use of the organ at the climax of both movements forge an immediate connection between them, but also the rising stepwise bass of the organ part in this closing section recalls the similar stepwise rising progression in the codetta of the first movement. ${ }^{38}$

Let us now look more closely at the harmonic design of this closing section. I have provided Roman numerals below the staff, indicating the mixed modality of the harmonic progression underlying the repeating vocal chorus. Of course, mixed modality is not at all uncommon in rock harmony; indeed, this is the same progression that had accompanied the chorus on its multiple statements during the course of the second movement. ${ }^{39}$ But what happens next is unusual: rather than continue to repeat the chorus at its original tonal level, the subdominant harmony that closes each statement pivots to become the dominant harmony of the tonality a whole step below, resulting in a large-scale descending-step sequence that quickly takes us far afield from the original key of E major. ${ }^{40}$

What is especially neat about this sequence is that it echoes, on a larger scale, the descending whole-step progression I-bVII-bVI that sounds at the beginning of each statement of the chorus riff. (I have suggested this in parentheses below the staff; on the second

37 For those unfamiliar with the term, the quodlibet (literally 'whatever you like') was a type of piece - especially popular in the seventeenth and eighteenth centuries - in which pre-existing familiar tunes were woven together with other contrapuntal strands to create a new piece, as in the thirtieth and final of J. S. Bach's Goldberg Variations (1742). Of course, quodlibet technique must always involve the composer making at least one strategic intertextual reference. One can find many examples of this in pop and rock, a famous one being the Beatles' weaving of 'Frère Jacques' into the vocal fabric of their 1966 hit 'Paperback writer' (we shall encounter another example later in this article).

38 The 'framing' compositional strategy of 'I've seen all good people' - moving from a quiet acoustic guitar introduction to a finale that begins with a heavy organ statement - is employed by Yes elsewhere, such as in 'Roundabout' from their follow-up album Fragile (1971). In fact, the inner chorus of 'Roundabout' (4:36 ff.) also involves a cumulative process: this chorus is different from its earlier appearances in that here it is merged with the distinctive groove from the contrasting middle section of the song (that is, the bass/guitar/organ triplet idea that began with the bass/guitar riff at 3:25 and was answered by the organ solo at 4:00).

39 The form of the second movement, 'All good people', is quite unusual in that it consists solely of a series of choruses without any verses or refrains.

40 While abrupt modulations by ascending semitone or whole tone have been a well-worn cliché of pop and rock songs since at least the 1960s - inspiring such colourful and varied descriptions as the 'truck driver's modulation' (see Everett, The Beatles as Musicians, 318-19), the 'pump-up' (see Ricci, 'A “Hard Habit to Break" ', and 'Barry Manilow tonality' (see McCreless, 'An Evolutionary Perspective', 106) - modulations by descending step are far less common. I am reminded here especially of the series of descending whole-step modulations in the final chorus of the Beach Boys' 'Good vibrations' (1966); see Harrison, 'After Sundown', 41-5. 
50 Spicer (Ac)cumulative Form in Pop-Rock Music
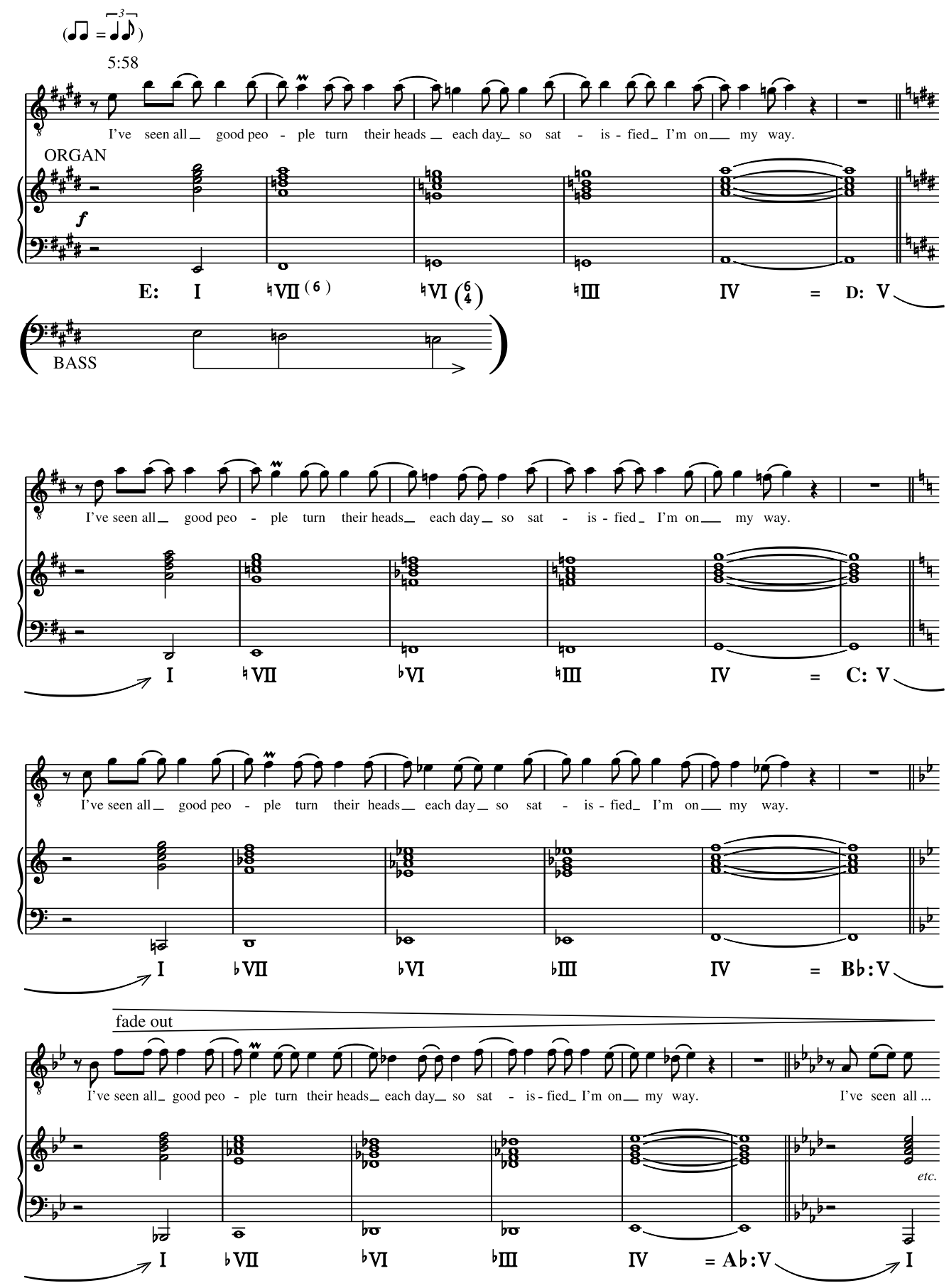

Example 4d 'All good people' (Chris Squire), coda. 
and subsequent statements, the bass actually does play these opening chords in root position.) Remember Robert Morgan's notion of the coda as a 'culmination', a 'final, predetermined conclusion' that the music is always aiming toward? It is almost as if the potential for this particular descending-step sequence were somehow lurking within the harmonic design of the chorus riff itself, but this potential is only fully realized - true to the spirit of cumulative form - in this full-fledged presentation of the sequence at the end of the track. The overall effect of the closing section is an infinite downward spiral, which would in fact return us to the home key of E major after six cycles through the sequence; this is left to our imagination, however, since the texture fades out soon after it moves into $\mathrm{A} b$ major.

We shall now jump forward over two decades to consider two tracks by British pop-rock groups from the 1990s. The first of these is complex, and will require several music examples to help illuminate its structure. By the mid-1990s, techno as a style had come a long way from its humble beginnings in the early 1980s. Prodigy's 'Break and enter', the opening track from their 1994 UK number one album Music for the Jilted Generation, is typical of the type of extended composition that 1990s techno groups were able to create using their ever-growing arsenal of synthesizers, sequencers, drum machines, samplers, and now, especially, computers. ${ }^{41}$ In Example 5a, I have taken the liberty of dissecting the work into its constituent riffs, which we shall examine first in isolation before putting them back together again. As we can see from this inventory, I have grouped the riffs into three categories unpitched riffs (that is, those generated by a drum machine), 'single-pitch' riffs, and pitched riffs, each labelled with one of the letters a to t. ${ }^{42}$ For the sake of consistency, I have shown all of the riffs in four-bar increments - corresponding to the length of most of the pitched riffs - although, strictly speaking, the majority of the unpitched and single-pitch riffs are actually only one bar in length, and constantly repeated to create larger four-bar units.

41 Formed in 1990 amidst the explosion of the British underground rave scene, Prodigy are a quartet in which only one of the four members actually plays any instruments - which might seem odd, especially considering that most of their music is exclusively instrumental. But this is actually quite typical of many of the newer techno groups: in Prodigy, Liam Howlett is the musical brainchild, composing and performing/recording all the music (with the aid of computer technology), while the three remaining members - Keith Flint, Maxim Reality, and Leeroy Thornhill - are mainly dancers, interpreting the songs visually both in live performance and, especially, in their innovative videos. (This is a tradition that can be traced back at least as far as the short-lived mid-1980s synth-pop quintet Frankie Goes to Hollywood, one of whose members, Paul Rutherford, was credited on the albums solely for his dancing.) Success in the US for Prodigy came three years later in 1997, when their The Fat of the Land album reached number one on Billboard's Top 200 (although it was essentially just an instrumental, the second single from this album, 'Smack my bitch up', caused quite a stir - as one might imagine - simply because of its title).

Fuelled by the use of Ecstasy and other mind-altering drugs, the dance culture that has grown up around techno - along with its myriad related styles such as 'acid house', 'electronica', and 'jungle' - in the UK over the past fifteen years or so is a complex and multi-faceted social phenomenon which has received considerable attention among recent scholars, mostly from those in cultural studies; see, for example, Gilbert and Pearson, Discographies. The music of techno, however, has until now received little serious analytical attention (a notable exception being the work of Mark Butler; see, for example, his 'Turning the Beat Around'.

42 Not included in this inventory for the sake of practicality (since they are almost impossible to notate) are a few riffs which have been sampled from television programmes and other 'real-life' sources, such as the distinctive wheezing sound of the TARDIS - the time machine from the long-lived BBC science fiction series Doctor Who - that appears towards the end of the main body of the track (5:14 ff.). 
52 Spicer (Ac)cumulative Form in Pop-Rock Music

\section{UNPITCHED RIFFS}

SHAKERS

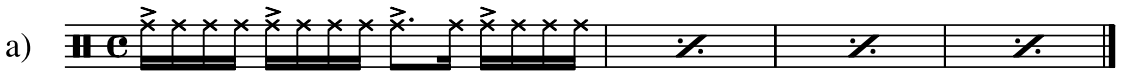

'WHIP'

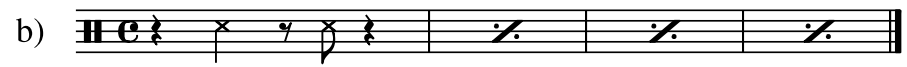

BASS DRUM

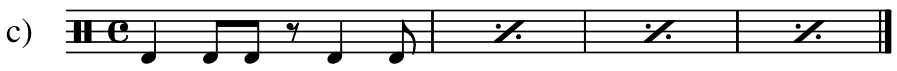

HI-HAT

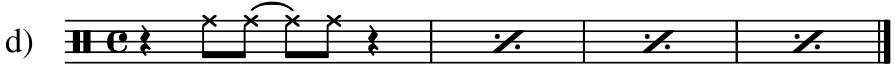

SAMPLED BREAKING GLASS

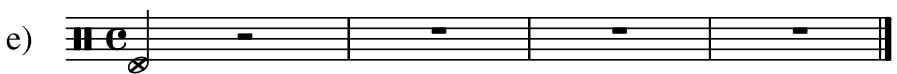

SAMPLED MACHINERY

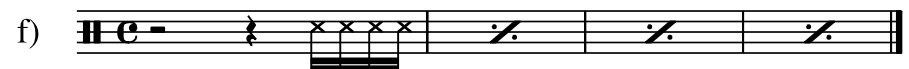

RIDE CYMBAL

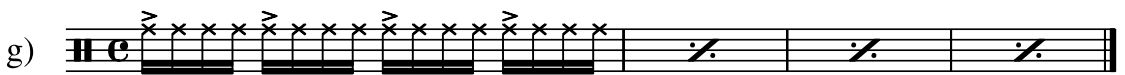

MUTED SNARE

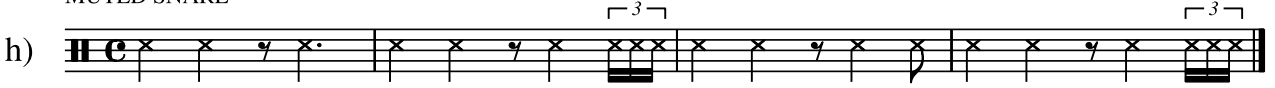

\section{'SINGLE-PITCH' RIFFS}

i)

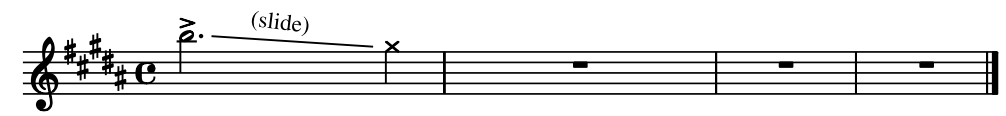

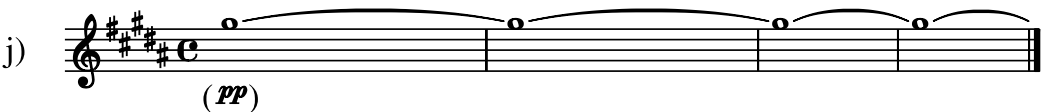

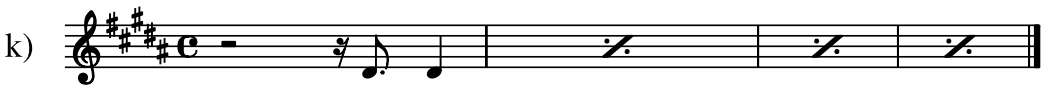

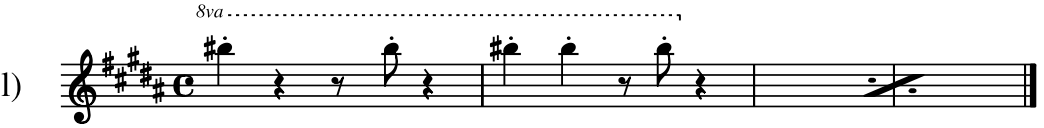

Example 5a Inventory of riffs.

Example 5 Prodigy, 'Break and enter' (1994). 


\section{PITCHED RIFFS}

STRING SYNTH

m)

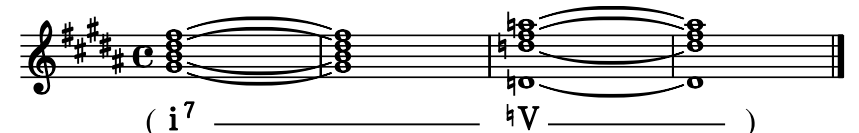

SYNTH

n)

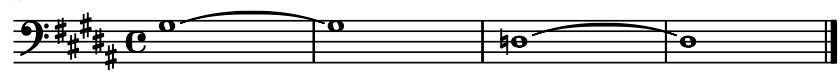

o)

\section{BASS SYNTH (ad lib)}

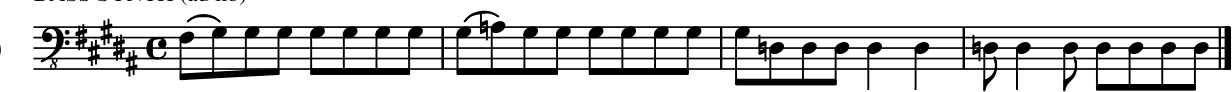

SAMPLED TEXTLESS FEMALE VOCAL (approximated)

p)

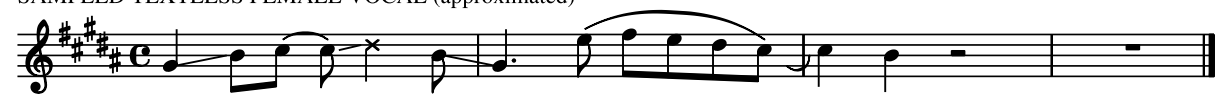

ANALOGUE SYNTH

q)

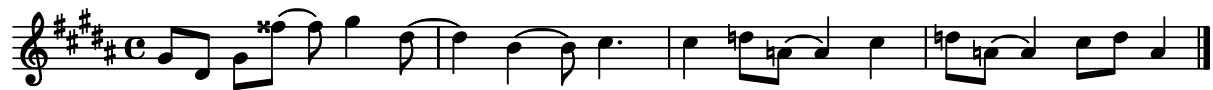

PERCUSSIVE SYNTH

r)

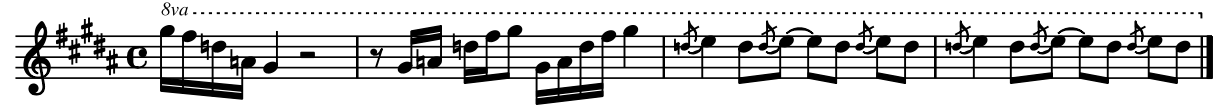

ANALOGUE SYNTH

s)
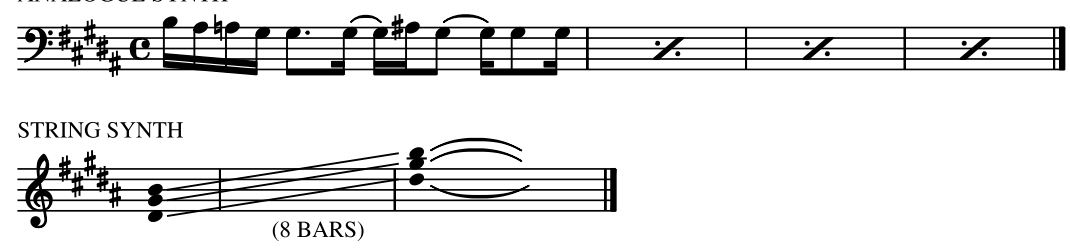

Example 5a continued

We shall return to this inventory of riffs in a moment, but let us now proceed to Example $5 \mathrm{~b}$, in which I have provided a formal synopsis of the entire track. 'Break and enter' is composed entirely of a series of short, self-contained accumulative forms, strung together to create a cohesive large three-part structure; I have labelled these three large parts as,

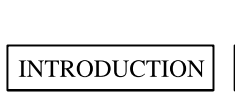

$1: 11$

\section{MAIN BODY of the TRACK}

OSCILLATION between $\mathrm{i}$ and $q \mathrm{~V}$ every two bars, punctuated by two short TONIC VAMPS

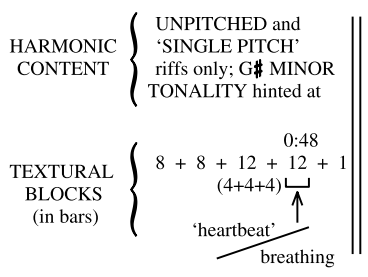

$6: 10$

CODA

Extended TONIC VAMP

$6: 24 \quad 6: 38$

$8+8+8+4+4+20+8+4+12$

$\stackrel{4}{\uparrow}$

rising strings

Example 5b Formal synopsis. 
respectively, the 'introduction', the 'main body' of the track, and the 'coda'. The short accumulative forms are, in turn, composed of a series of textural 'blocks' of varying lengths (much like the accumulative beginning of the Alan Parsons Project's 'I Robot', discussed above); this is indicated in the formal synopsis by way of a series of numbers $(8+8+12 \ldots)$, corresponding to the length of each of these blocks in bars. When one or more new riffs are added into the texture it always marks the beginning of a new block; however - and this is an important difference from what we have seen in previous examples - the beginning of a new block can also be marked by the subtraction of one or more riffs from the texture. Since the normative length for the riffs is four bars, it follows that the length of each block will always be a multiple of four (four, eight, twelve, and so on); the only exception to this is the 'one-bar block' at the end of the introduction - actually one bar of silence in which all the parts drop out to clear the air before the onset of the main body of the track.

Let us now look back at the inventory of riffs more closely (Example 5a). You will notice that I have notated all of the single-pitch and pitched riffs using a key signature of five sharps, suggesting a key of $G \#$ minor. While 'Break and enter' is most definitely in $G \#$, this tonality is by no means projected in a conventional manner. Notice that the first three of the single-pitch riffs (i-k) project the pitches $\mathrm{b}^{2}, \mathrm{~g} \sharp^{2}$, and $\mathrm{d} \sharp^{1}$ - corresponding respectively to the third, root, and fifth of a G\# minor triad. During the introduction (the first minute or so of the track), only these single-pitch riffs are layered into the texture along with the unpitched riffs, therefore hinting at the tonic $\mathrm{G} \#$ minor without establishing it unequivocally. ${ }^{43}$

The first two of the pitched riffs, $m$ and $n$, together illustrate the oscillating two-chord vamp that governs most of the main body of the track: a $G \#$ minor seventh chord $\left(\mathrm{i}^{7}\right)$

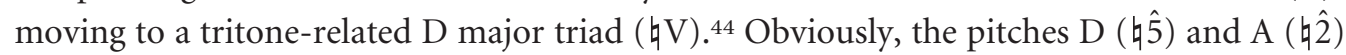
of the D major triad lie outside a conventional $G \#$ minor framework, suggesting instead a kind of locrian mixture wherein the dominant chord is built on the lowered fifth scale degree. ${ }^{45}$ Most of the pitched riffs in 'Break and enter' seem to be built around this oscillating two-chord progression: for example, the angular analogue synth riff q arpeggiates the tonic triad in its first two bars, and likewise the $q \mathrm{~V}$ chord in its third and fourth bars (spiced up with the accented incomplete neighbour notes $\mathrm{F} \mathbf{x}$ and $\mathrm{C} \#$ ). But look closely at riff $r$, played on what I call the 'percussive synth': in its first two bars, a D major triad is nested within a descending/ascending arpeggiated flourish bounded at its upper

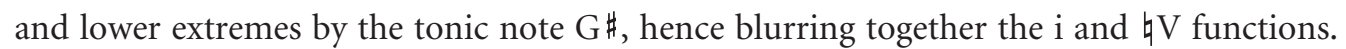
Space does not permit me to analyse every one of the riffs in minute detail, but it should

43 The $b \sharp^{3}$ of riff (l) is actually the major third of a $G \sharp$ triad, and yet since it sounds in such a high register it has the effect of an upper harmonic which, at least to my ears, does not negate the feeling of $\mathrm{G} \#$ minor when it is layered into the texture.

44 While I seriously doubt that Liam Howlett was aware of this, the $\mathrm{i}^{7}-b \mathrm{~V}$ progression as a whole is an octatonic subset - specifically, Forte set 6-Z50 [2,3,6,8,9,11] from Collection II.

45 An emphasis on dissonant tritone and semitonal relationships seems to be a characteristic of the harmonic language of many techno tracks: for example, also on Music for the Jilted Generation, Prodigy build the main groove of their 'Full throttle' around another oscillating two-chord vamp, I- $b$ II, featuring phrygian mixture.

The twisted, tritone-related 'dominant' ( $b \mathrm{~V}$ ) has been discussed by Timothy Jackson as a characteristic feature of Tchaikovsky's symphonic works; see his 'Aspects of Sexuality and Structure'. Unlike Jackson, however, I will resist the temptation to speculate as to how this 'deviant' progression might reflect on the composer's sexuality. 
suffice to say that as these riffs are layered in and out of the texture against one another, what often results is a sense of conflicting modality - for example, G\# Aeolian against G\# Locrian - between two or more riffs occupying their own distinctive registral spaces. ${ }^{46}$

Now that we have a sense of how the large-scale formal design of 'Break and enter' is constructed (I shall discuss the strategy of the coda a little later), let us now move in for a closer look at the design of some of the short accumulative forms within this larger structure. Example $5 \mathrm{c}$ shows the accumulative beginning of the track. As mentioned above, the introduction consists solely of unpitched and single-pitch riffs. The first two textural blocks organize the unpitched riffs into two distinctive layers of three riffs each: the track opens with a composite of riffs $(\mathrm{a}-\mathrm{c})$, followed in bar 9 by the addition of a similar composite of riffs $(d-f)$. After another eight bars, riffs g and $i$ are layered in to the texture, and the short accumulative form is now complete. ${ }^{47}$

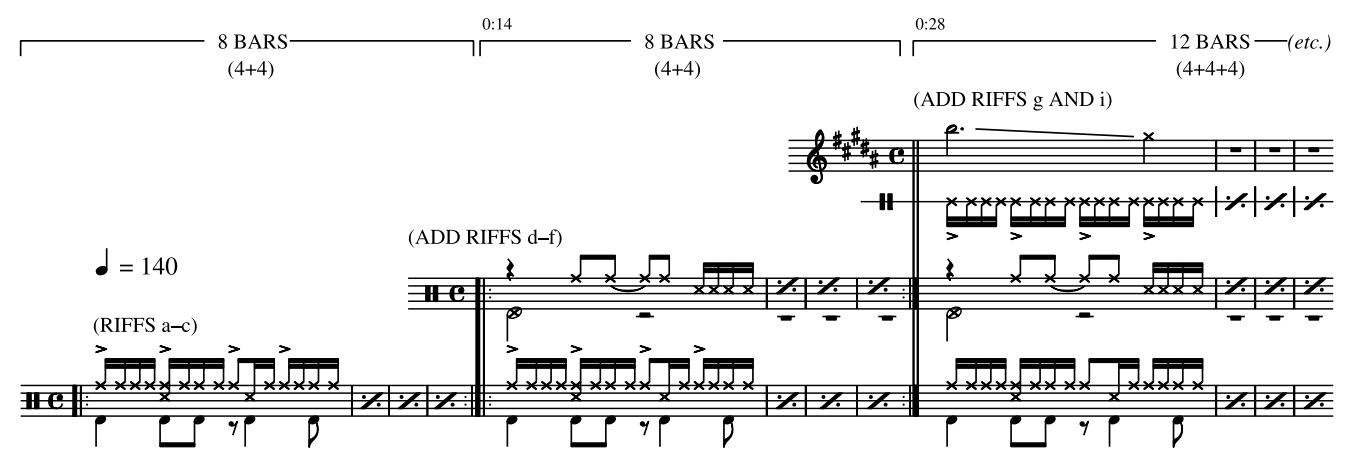

Example 5c Introduction: opening bars.

Example 5d shows the beginning of another short accumulative form taken from the main body of the track (2:14 ff.). What marks the opening of this small form is the sudden disappearance of all the drum-machine riffs, which spotlights the introduction of the aforementioned angular analogue synth riff q, accompanied by a chordal backdrop of riffs $\mathrm{m}-\mathrm{n}$. After eight bars, two additional riffs $-\mathrm{p}$ and $\mathrm{g}-$ are layered in to the texture. Riff $\mathrm{p}$ is especially interesting in that it features a sample of a textless female vocal, the only 'sung' music in the entire track. The use of vocal samples is a defining characteristic of many techno tracks, as Jeremy Gilbert and Ewan Pearson have explained:

[T] hese forms stand out in the history of recorded 'popular' music in that they eschew verbal meaning. Most house and techno tracks have no lyrics. Vocal

46 This effect in 'Break and enter' reminds me of a similar effect achieved in much of Benjamin Britten's music, what Philip Rupprecht has described as 'modal stratification'; see his 'Tonal Stratification and Uncertainty'.

47 Not shown in Example $5 \mathrm{c}$ is the twelve-bar block that immediately follows, where the texture abruptly thins to just the bass drum riff $\mathrm{c}$ - muffled in the mix so as to sound like a 'heartbeat' - accompanied by the held tonic note of riff $\mathrm{j}$. 


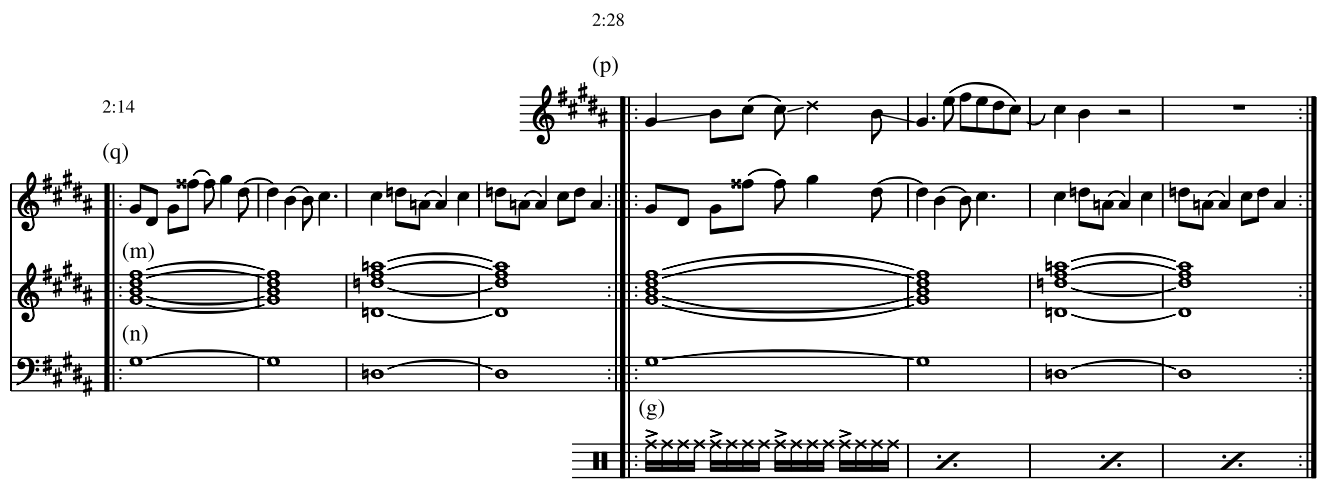

Example 5d Main body of the track, from 2:14.

samples are used as pieces of sound rather than as meaningful phrases. The fact that dance music is a new form of popular instrumental music is what makes it so striking: it is a music which is not based on songs. ${ }^{48}$

Example 5e highlights another section from the main body of the track, in which the aforementioned 'percussive synth' riff $r$ is introduced for the first time (3:51 ff.). As seems now to be the normative pattern, riffs $\mathrm{p}$ and $\mathrm{m}$ are added to the texture after eight bars

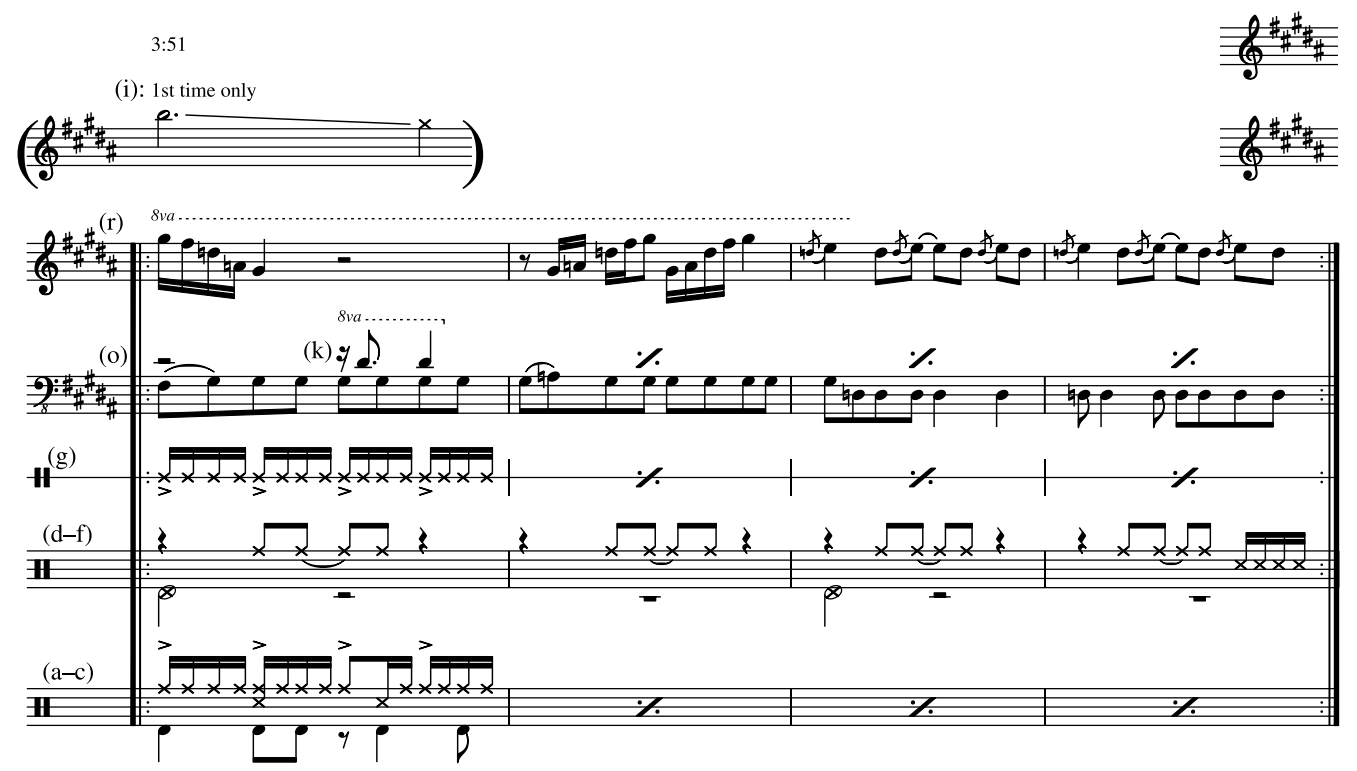

Example 5e Main body of the track, from 3:51.

48 Gilbert and Pearson, Discographies, 38 (their emphasis). Gilbert and Pearson's notion of 1980s-90s dance music as a new form not based on songs is somewhat misleading in that it seems to forget the long-standing tradition of instrumental big-band dance music made popular during the swing era, two famous examples being Glenn Miller's 'In the mood' (1939) and Billy Strayhorn's 'Take the A train' (1941). 
(4:05 ff.). It will be noticed, however, that here each of these riffs has been truncated, so that only the first half of the $\mathrm{p}$ riff is heard, and only the second half of the $\mathrm{m}$ riff. While this may have been intended by the composer simply as another means of providing a sense of constant variety within an otherwise highly repetitive structure (and therefore delighting the ears of a crowd of tripping, dancing ravers), it may also have been due to the fact that the $\mathrm{i}^{7}$ chord which sounds during the first two bars of the complete version of riff $m$ would have 'clashed' with the pitch content (specifically, $\downarrow \hat{5}$ ) of the descending/ascending locrian flourish in the first two bars of riff $\mathrm{r}$.

Finally, Example $5 \mathrm{f}$ highlights a section from the coda. It will be recalled that the harmonic design of the main body of the track was characterized by a constant oscillation back and forth between $\mathrm{i}^{7}$ and $\downarrow \mathrm{V}$; however, as I have shown in the formal synopsis (Example $5 \mathrm{~b}$ ), this oscillating progression is temporarily relieved by way of two short passages - of four bars (2:07 ff.) and sixteen bars ( $4: 47 \mathrm{ff}$.) respectively - where the harmony remains static on the tonic. In the coda, this idea of 'vamping on the i' entirely takes over as a way of harmonically 'winding down' the track. ${ }^{49}$ During the coda's second eight-bar block (immediately prior to what is shown in Example 5f), a new riff t emerges, consisting of a held G\# minor triad (played by synthesized strings) that gradually slides upwards through one octave (an effect likely created using a portamento device). As we can see, this sliding chord reaches its higher

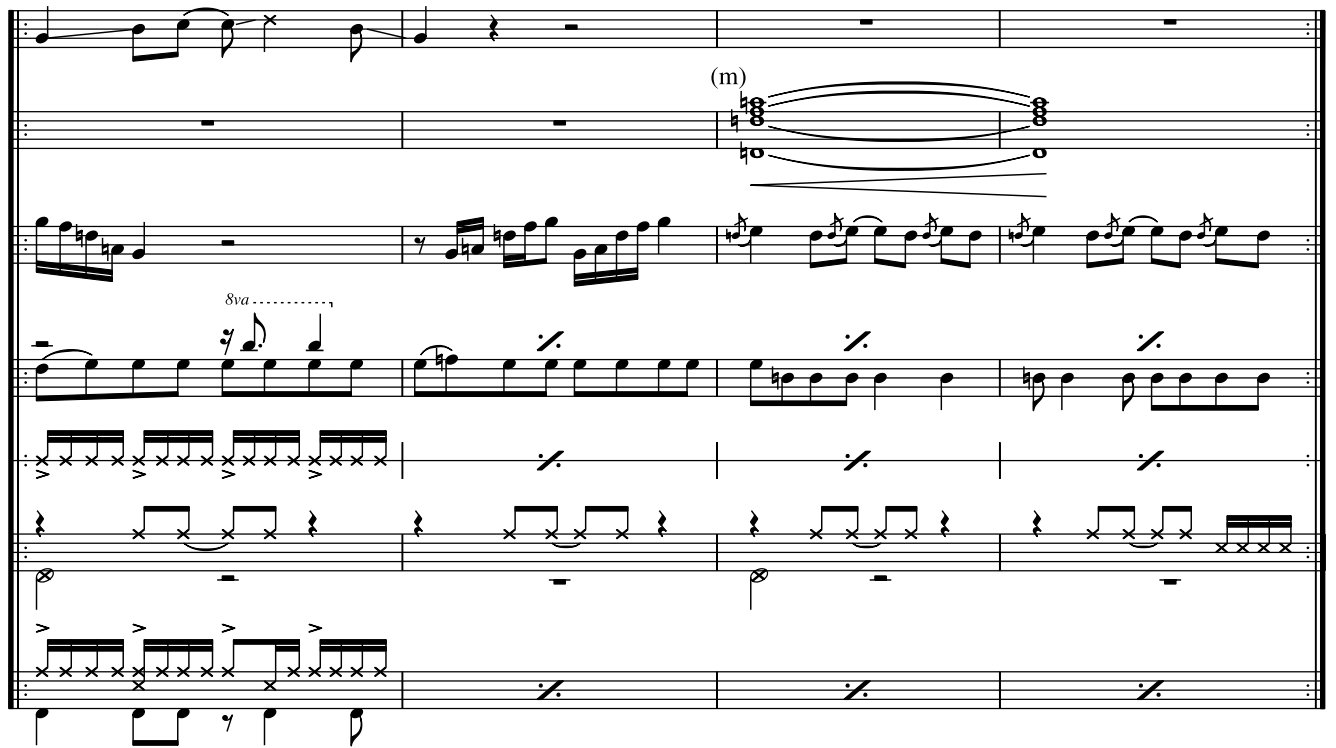

Example 5e continued

49 One encounters a similar strategy in nineteenth-century classical pieces. I am reminded, for example, of Chopin's Berceuse, Op. 57 (1843-4), where the I- $\mathrm{V}^{7}$ oscillating progression pervasive throughout the piece winds down to become a tonic vamp in the closing bars. For a detailed analysis of the Berceuse, see Korsyn, 'Towards a New Poetics of Musical Influence', 18-30. 


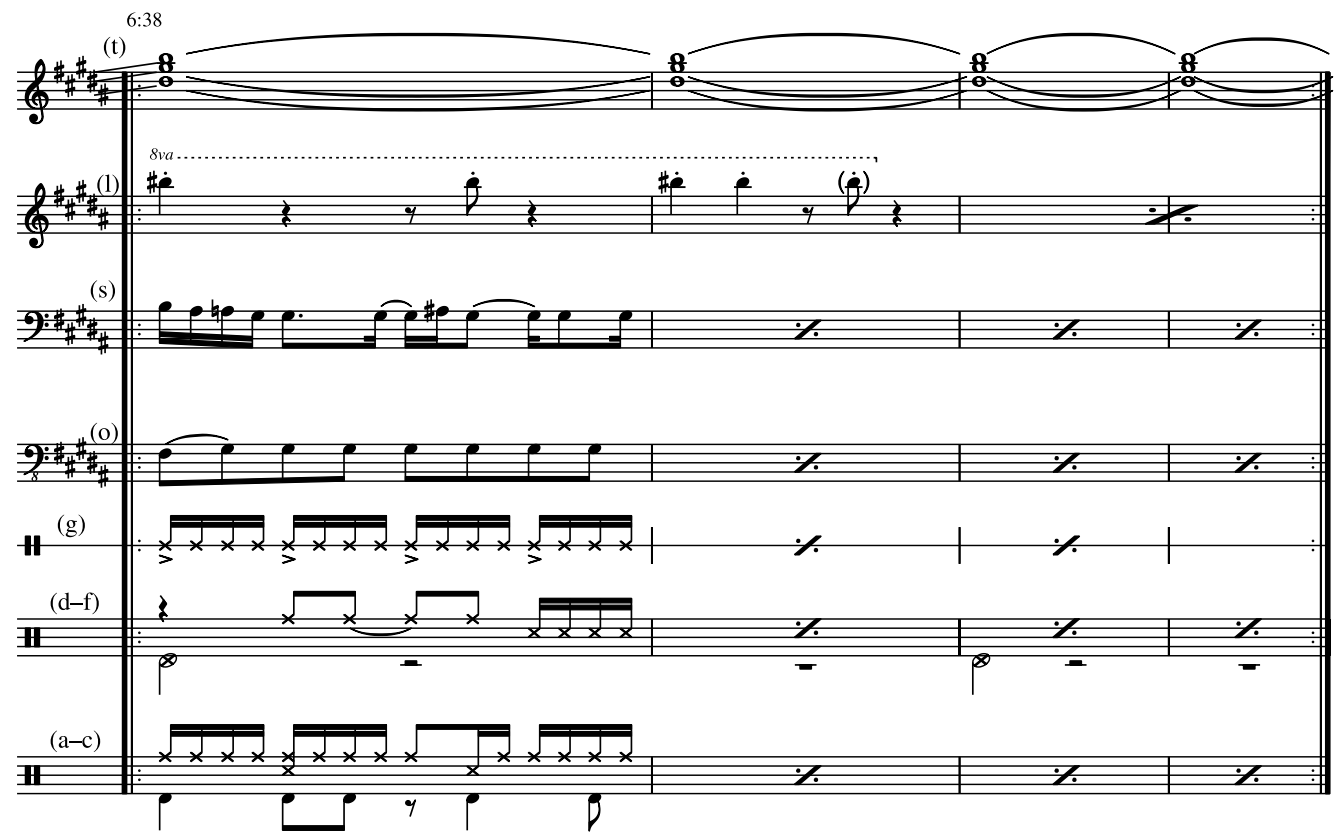

Example 5f Coda, from 6:38.

octave exactly at the onset of the next textural block; indeed, one might argue that this is the 'moment of culmination' toward which the track has been ever unfolding. And here, the last of our pitched riffs (s) is introduced, consisting of a repeating one-bar synth motive that traces a descending chromatic path between $\hat{3}$ and $\hat{1}$, hence reinforcing the prevailing tonic vamp.

Before we leave 'Break and enter', I should point out that the series of textural blocks is more erratic during the coda than at any other point in the track: whereas the main body of the track consists mostly of eight-bar blocks, in the coda (see Example 5b) the consistent series of eight-bar blocks soon breaks down (into $4+4+20+8$, and so on). In addition to the length of the blocks becoming more erratic, the onset of each new block is now marked mainly by subtracting riffs from the texture, which conveys an overall impression of the track disintegrating into nothingness.

In all of the previous examples, the (ac)cumulative form has resulted in some way or another from a gradual process of textural growth, be it over just the opening section of the track or the course of an entire song. While this seems to be by far the preferred method, not all cumulative forms in pop and rock rely solely on such a process. Another important type of large-scale cumulative form can be found in songs where the prevailing compositional strategy seems to involve aiming towards a climactic final section, one in which two or more distinctive melodies that had previously been heard separately are made to sound in counterpoint against one another. The resultant effect in such songs, at least to my ears, is usually as if these separate melodies were somehow always destined to 
fit together, and once this has been achieved then musically the song has nowhere else to go. A famous early example of this technique can be found in Paul McCartney's Beatles song 'Eleanor Rigby' (1966), where Paul overdubs himself singing the melody of the chorus sotto voce above the melody of the refrain only for the song's final section. Indeed, many British pop-rock composers have exploited a similar cumulative strategy in their songs. ${ }^{50}$ None, however, is more striking than the magnificent finale to the 1997 mega-hit 'Tubthumping' by the self-professed 'anarchist collective' Chumbawamba. ${ }^{51}$

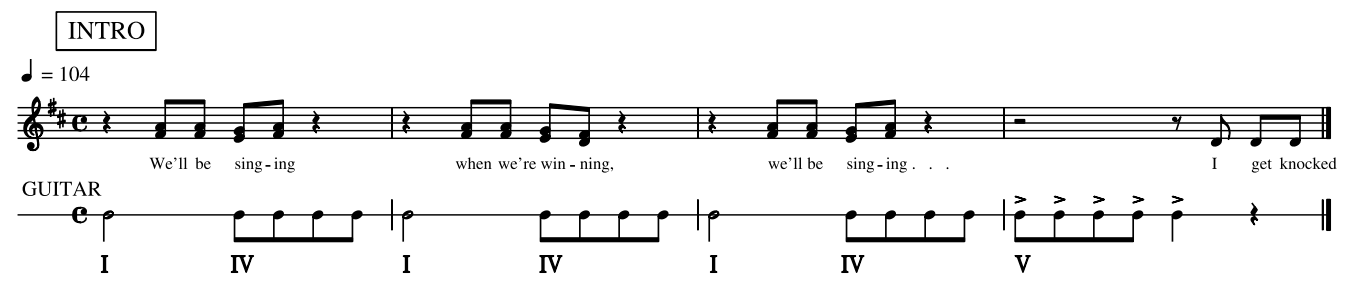

\section{CHORUS}

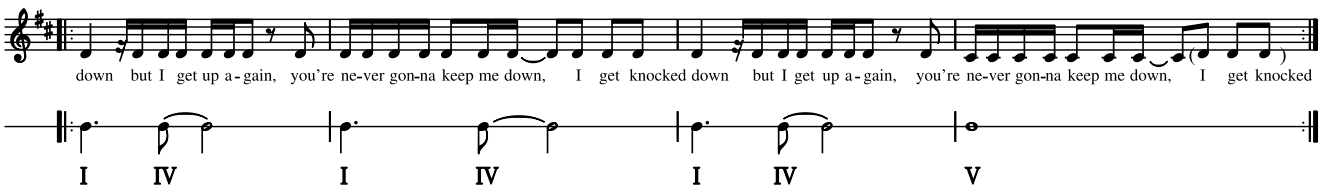

VERSE 1

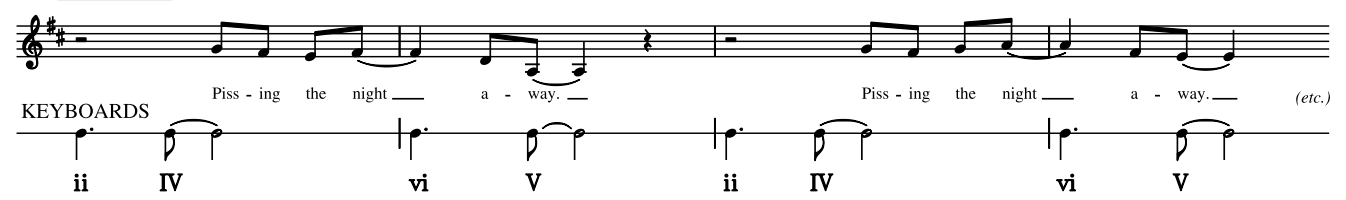

Example 6a An abridged score.

Example 6 Chumbawamba, 'Tubthumping' (1997). Words and music by Nigel Hunter, Bruce Duncan, Alice Nutter, Louise Watts, Paul Greco, Darren Hamer, Allen Whalley, and Judith Abbott. @ 1997 EMI, Germany GMBH. All rights in the United States and Canada controlled and administered by EMI Blackwood Music Inc. All rights reserved. International Copyright secured. Used by permission.

50 I could cite dozens of examples of British pop-rock songs in which melodies that had previously only been heard separately are combined in a cumulative texture at the end of the track, but three of my favourites will have to suffice (listed here in chronological order): Manfred Mann's cover of Bruce Springsteen's 'Blinded by the light' (1976); [the] Buggles' 'Video killed the radio star' (1979); and Tears for Fears' 'Everybody wants to rule the world' (1985). Each of these songs also exploits a variety of other accumulative or cumulative procedures.

51 As of the week ending 31 January 1998, 'Tubthumping' had fallen to the number two spot, having spent nine consecutive weeks at number one on Billboard's 'Hot 100 Airplay' chart. It was the breakthrough single for Chumbawamba in the US, where until then they had remained virtually unknown despite being an underground favourite in their native Britain and in Europe for almost fifteen years. 'Tubthumping' has, sadly, since proved to be Chumbawamba's only US hit, clocking in at number 23 on VH1's 2002 list of the 100 Greatest 'One Hit Wonders' of the rock era. The band give their own definition for the song's title in the liner notes for their album Tubthumper: 'Tubthumping is Shouting to Change the World (then having a drink to celebrate). It's stumbling home from your local bar, when the world is ready to be PUT RIGHT'. 
As I have shown in the abridged score (Example 6a), the song begins with a four-bar introduction, featuring a duet by two of the female members ('we'll be singing when we're winning') over a sparse, jangly electric guitar accompaniment. These introductory bars have been mixed so as to sound deliberately muffled, as if coming from a TV speaker with the volume turned down. Following this introduction, we hear the chorus of the song for the first time ('I get knocked down, but I get up again ...') chanted by several of the band members in unison. In stark contrast to the introduction, the texture of the chorus is immediately massive: loud, distorted electric guitar power chords and a bass-and-snare-heavy hip-hop drum beat threaten to overpower the vocals, which in themselves already border on shouting rather than singing (the band members even go so far as to use megaphones while singing the chorus in live performances of the song).

With the subsequent entrance of the first verse the texture again changes drastically. Although the drum beat continues at the forefront, the loud guitar power chords are replaced by soft, lush keyboards and the prevailing harmonic undercurrent of I-IV . . V gives way to the darker ii-IV-vi-V, over which a lone female voice sings nonchalantly of 'pissing the night away' (i.e., the heavy drinking at the local pub that is the usual accompaniment to a good night of tubthumping). Chumbawamba have by this point established the textural dichotomy of the song: huge, brash choruses are alternated with quieter, contemplative verses. This pattern of chorus-verse cycles three times, with a calypso-flavoured trumpet solo taking the place of the vocal in the third verse.

In the final chorus of 'Tubthumping', the large-scale cumulative form of the song is confirmed (Example 6b). Up to this point the respective melodies of the introduction, chorus, and verse have been isolated from one another, but here all three tunes are made to sound together in one colossal composite texture (notice that on the fifth repetition of the final chorus the solo trumpet is even thrown back into the soup, only this time - in another example of quodlibet technique - it plays the quintessentially British-sounding theme of Jeremiah Clarke's Trumpet Voluntary). ${ }^{52}$ To be sure, this composite texture is far removed from an elaborate four-part Bachian counterpoint - but it is cleverly constructed none the less. On listening to the final chorus, one can distinguish clearly each of the four melodies in spite of the surrounding chaos. Chumbawamba have achieved this effect by carefully combining tunes with markedly different rhythmic profiles, profiles that retain their individual identity against the backdrop of the other parts (a technique not unlike Mozart's typical strategy for distinguishing multiple characters that are made to sing different melodies and words all at once during the finales of his operas). But what makes this particular use of cumulative form all the more effective is that it amplifies perfectly the underlying message of the song: after a long night of drinking, presumably everyone at the pub is eager to get up and have a good 'tubthump' - and so they do in the final chorus, all at the same time.

52 The quotation of the Trumpet Voluntary appears in its original key of D major. The use of a Baroque trumpet during a song's finale has a venerable history in British popular music, owing an allegiance to the Beatles. I am reminded of both the final chorus to 'Penny Lane' and, of course, the cumulative swirl of international quotations during the final chorus of 'All you need is love', which includes a piccolo trumpet playing the tune to Bach's Two-Part Invention in F, transposed up a tone so as to fit the G major key of the song (for a detailed intertextual analysis of 'All you need is love', see my 'Strategic Intertextuality'. 


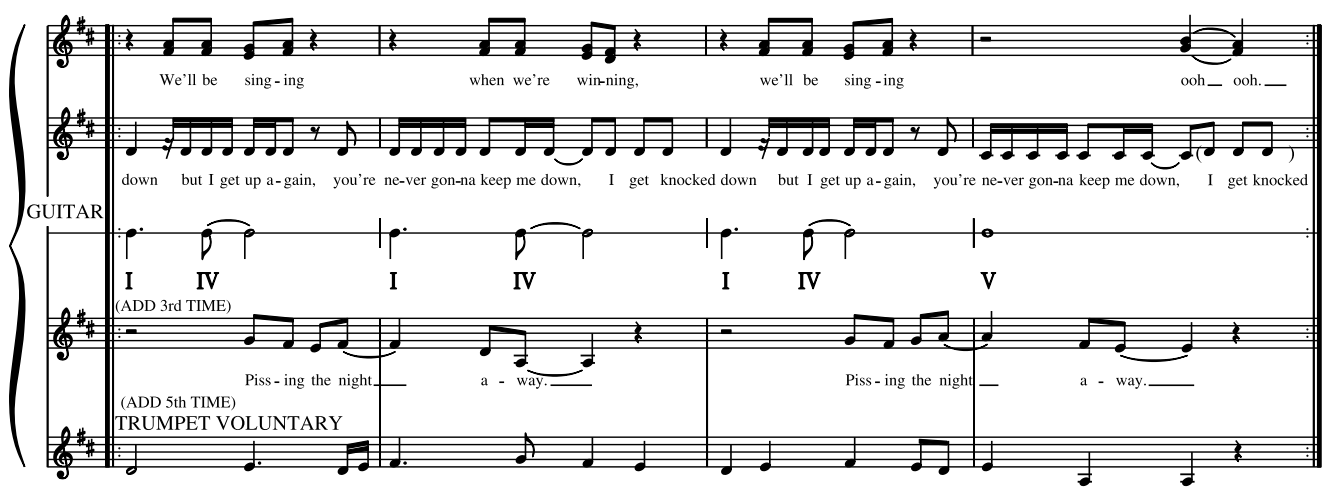

Example 6b. Cumulative swirl in the final chorus.

While I do not claim to have been exhaustive, I hope that this analytical sampler - drawing upon a diversity of styles ranging from progressive rock to post-punk to techno - has illuminated some of the ways in which accumulative and cumulative forms have proven time and again to be effective strategies for making pop-rock songs throughout the post-Beatles era. Most importantly, the use of such forms can be seen as perhaps the primary means by which pop-rock composers have been able to transcend the predictable boundaries of simple verse-chorus patterns in their songs.

In highlighting the differences between spatial and temporal metaphors as they have been applied to musical form, David Brackett reminds us (echoing Morgan's Wagnerian ideal) that '[pop-rock] recordings tend to foreground the temporality of the music text'. ${ }^{53}$ This seems to be especially true of recordings that feature (ac)cumulative forms: whether the accumulation occurs over just a small section of the song or across an entire track, the listener is pulled into the formal process as it unfolds in real time. We are made to experience the joy of anticipation - and indeed, that moment of sheer delight when the point of culmination is finally reached.

\section{Discography}

What follows is a list of all the records analysed or cited in the article (in the case of singles, the B side is listed along with the A side only if it is analysed or cited). The month/year and catalogue information corresponds to that of the original UK release except where noted.

The Beach Boys. Oct. 1966. 'Good vibrations'. Capitol: 5676 (US release).

The Beatles. Oct. 1962. 'Love me do'. Parlophone: R 4949.

—. Jan. 1963. 'Please please me'. Parlophone: R 4983.

—. Mar. 1963. Please Please Me. Parlophone: PCS 3042.

—. Apr. 1963. 'From me to you'. Parlophone: R 5015.

—. Aug. 1963. 'She loves you'. Parlophone: R 5055.

—. Nov. 1963. 'I want to hold your hand'. Parlophone: R 5084.

—. June 1966. 'Paperback writer'. Parlophone: R 5452.

—. Aug. 1966. Revolver. Parlophone: PCS 7009.

—. Feb. 1967. 'Penny Lane/Strawberry fields forever'. Parlophone: R 5570.

—. July 1967. 'All you need is love'. Parlophone: R 5620.

53 Brackett, Interpreting Popular Music, 24 (his emphasis). 


\section{Spicer (Ac)cumulative Form in Pop-Rock Music}

—. Apr. 1969. 'Get back'. Apple: R 5777.

—. Sept. 1969. Abbey Road. Apple: PCS 7088.

—. May 1970. Let It Be. Apple: PCS 7096.

[The] Buggles. c.Sept. 1979. The Age of Plastic. Island: 842849 (US catalogue).

Chumbawamba. Aug. 1997. 'Tubthumping'. EMI: EM 486.

—. Sept. 1997. Tubthumper. EMI: EMC 3773.

The Clash. Dec. 1979. London Calling. CBS: CLASH.

Phil Collins. Jan. 1981. 'In the air tonight'. Virgin: VSK 102.

Deep Purple. Apr. 1972. Machine Head. Purple: TPSA 7504.

Peter Gabriel. Mar. 1977. 'Solsbury Hill'. Charisma: CB 301.

Genesis. Oct. 1972. Foxtrot. Charisma: CAS 1058.

—. Mar. 1980. Duke. Charisma: CBR 101.

- Sept. 1981. Abacab. Charisma: CBR 102.

—. Aug. 1983. 'Mama'. Virgin: MAMA 1.

The Human League. Oct. 1981. Dare. Virgin: T 2192.

Kraftwerk. May 1978. The Man Machine. Capitol: EST 11728.

Led Zeppelin. Nov. 1971. IV. Atlantic: 2401012.

Manfred Mann's Earth Band. Aug. 1976. 'Blinded by the light'. Bronze: BRO 29.

Van Morrison. Mar. 1970. Moondance. Warner Brothers: WS 1835.

New Order. Mar. 1983. 'Blue Monday'. Factory: FAC 73 (12").

—. May 1985. Low-life. Factory: FACD 100.

—. Oct. 1986. Brotherhood. Factory: FACD 150.

Mike Oldfield. May 1973. Tubular Bells. Virgin: T 2001.

—. Sept. 1974. Hergest Ridge. Virgin: V 2013.

Orchestral Manoeuvres in the Dark. Feb. 1980. Orchestral Manoeuvres in the Dark. Dindisc: DID 2.

Orgy. Feb. 1999. 'Blue Monday'. F111: 44555 (US release).

The Alan Parsons Project. June 1977. I Robot. Charisma: SPARTY 1012.

Pink Floyd. Mar. 1973. The Dark Side of the Moon. Harvest: SHVL 804.

The Plastic Ono Band. July 1969. 'Give peace a chance'. Apple: APPLE 13.

The Police. Oct. 1979. Reggatta de Blanc. A\&M: AMLH 64792.

- Oct. 1980. Zenyatta Mondatta. A\&M: AMLH 64831.

- Oct. 1981. Ghost in the Machine. A\&M: AMLK 63730.

[The] Prodigy. July 1994. Music for the Jilted Generation. XL: XLCD 114.

- July 1997. The Fat of the Land. XL: XLCD 121.

Queen. Nov. 1975. 'Bohemian rhapsody'. EMI: EMI 2375.

Radiohead. June 1997. OK Computer. Parlophone: CDNODATA 02.

—. Oct. 2000. Kid A. Capitol: CDP 27753 (US catalogue).

—. June 2001. Amnesiac. Capitol: CDP 32764 (US catalogue).

- June 2003. Hail to the Thief. Capitol: CDP 84543 (US catalogue).

The Rolling Stones. Jan. 1967. 'Let's spend the night together'/'Ruby Tuesday'. Decca: F 12546.

The Specials. June 1981. 'Ghost town'. Chrysalis-2-Tone: CHSTT 17.

Squeeze. Feb. 1978. 'Take me I’m yours'. A\&M: AMS 7335.

- Nov. 1996. Excess Moderation. A\&M: 540651-2.

Tears For Fears. Mar. 1985. 'Everybody wants to rule the world'. Mercury: IDEA 9.

10cc. May 1975. 'I'm not in love'. Mercury: 6008014.

Pete Townshend. June 1980. 'Let my love open the door'. Atco: 7217 (US release).

The Who. Sept. 1971. Who’s Next. Track: 2408102.

—. July 1978. 'Who are you'. Polydor: WHO 1.

—. Feb. 1981. 'You better you bet'. Polydor: WHO 4.

Wings. July 1978. 'With a little luck'. Parlophone: R 6019.

Yaz[oo]. Aug. 1982. Upstairs at Eric's. Mute: STUMM 7.

Yes. Mar. 1971. The Yes Album. Atlantic: 2400101.

—. Nov. 1971. Fragile. Atlantic: 2401019.

—. Sept. 1977. 'Wonderous stories'. Atlantic: K 10999 (12").

\section{Bibliography}

Barrow, Steve, and Peter Dalton. Reggae: the Rough Guide. London: Rough Guides, 1997.

Brackett, David. Interpreting Popular Music. Cambridge: Cambridge University Press, 1995. Repr. Berkeley:

University of California Press, 2000. 
Burkholder, J. Peter. All Made of Tunes: Charles Ives and the Uses of Musical Borrowing. New Haven and London: Yale University Press, 1995.

—. 'Cumulative Form in Ives and Others'. Paper presented at the Annual Meeting of the American Musicological Society, New York, 1995.

Burns, Lori. 'Analytic Methodologies for Rock Music: Harmonic and Voice-Leading Strategies in Tori Amos's "Crucify", in Expression in Pop-Rock Music: a Collection of Critical and Analytical Essays, ed. Walter Everett. New York: Garland, 2000. 213-46.

Butler, Mark J. 'Turning the Beat Around: Reinterpretation, Metrical Dissonance, and Asymmetry in Electronic Dance Music', Music Theory Online 7/6 (2001), <www.societymusictheory.org/mto/issues/mto.01.7.6/ mto.01.7.6.butler_frames.html>.

Cohn, Richard. 'Transpositional Combination of Beat-Class Sets in Steve Reich's Phase-Shifting Music', Perspectives of New Music 30 (1992), 146-77.

Darcy, Warren. 'Creatio ex nihilo: the Genesis, Structure, and Meaning of the Rheingold Prelude', 19th Century Music 13 (1989), 79-100.

Everett, Walter. The Beatles as Musicians: Revolver through the Anthology. New York: Oxford University Press, 1999.

- 'Confessions from Blueberry Hell, or, Pitch Can Be a Sticky Substance', in Expression in Pop-Rock Music, ed. Everett. New York: Garland, 2000. 269-345.

- The Beatles as Musicians: The Quarry Men through Rubber Soul. New York: Oxford University Press, 2001.

Forte, Allen. The Structure of Atonal Music. New Haven and London: Yale University Press, 1973.

- The American Popular Ballad of the Golden Era 1924-1950. Princeton: Princeton University Press, 1995.

Frith, Simon. 'The Coventry Sound - The Specials', in Music for Pleasure: Essays in the Sociology of Pop. New York: Routledge, 1988. 77-80.

Gilbert, Jeremy, and Ewan Pearson. Discographies: Dance Music, Culture and the Politics of Sound. New York: Routledge, 1999.

Goodwin, Andrew. Dancing in the Distraction Factory: Music Television and Popular Culture. Minneapolis: University of Minnesota Press, 1992.

Harrison, Daniel. 'After Sundown: the Beach Boys' Experimental Music', in Understanding Rock: Essays in Musical Analysis, ed. John Covach and Graeme M. Boone. New York: Oxford University Press, 1997. $33-57$.

Holm-Hudson, Kevin. '(Re)mixing as (Re)orchestration: Textural Revision in Mike Oldfield's Hergest Ridge'. Paper presented at the Annual Meeting of the Society for Music Theory, Atlanta, 1999.

Hubbs, Nadine. 'The Imagination of Pop-Rock Criticism', in Expression in Pop-Rock Music, ed. Everett. New York: Garland, 2000. 3-29.

Jackson, Timothy. 'Aspects of Sexuality and Structure in the Later Symphonies of Tchaikovsky', Music Analysis 14 (1995), 3-25.

Korsyn, Kevin. 'Towards a New Poetics of Musical Influence', Music Analysis 10 (1991), 3-72.

Macan, Edward. Rocking the Classics: English Progressive Rock and the Counterculture. New York: Oxford University Press, 1997.

McCreless, Patrick. 'An Evolutionary Perspective on Nineteenth-Century Semitonal Relations', in The Second Practice of Nineteenth-Century Tonality, ed. William Kinderman and Harald Krebs. Lincoln: University of Nebraska Press, 1996. 87-113.

Middleton, Richard, ed. Reading Pop: Approaches to Textual Analysis in Popular Music. New York: Oxford University Press, 2000.

Moore, Allan F. 'The So-called “Flattened Seventh” in Rock', Popular Music 14 (1995), 185-201.

Morgan, Robert P. 'Coda as Culmination: the First Movement of the "Eroica”" Symphony', in Music Theory and the Exploration of the Past, ed. Christopher Hatch and David W. Bernstein. Chicago: University of Chicago Press, 1993. 357-76.

New Order. Substance. Warner Reprise Video 38152-3 (1989).

Newman, Richard. The Making of Mike Oldfield's Tubular Bells. London: Music Maker Books, 1993.

Regev, Motti. 'The "Pop-Rockization" of Popular Music', in Popular Music Studies, ed. David Hesmondhalgh and Keith Negus. London: Arnold, 2002. 251-64.

Ricci, Adam. 'A "Hard Habit to Break": the Integration of Harmonic Cycles and Voice-Leading Structure in Two Songs by Chicago', Indiana Theory Review 21 (2000), 129-46.

Rupprecht, Philip. 'Tonal Stratification and Uncertainty in Britten's Music', Journal of Music Theory 40 (1996), 311-46.

Southall, Brian. Abbey Road: the Story of the World's Most Famous Recording Studios. Cambridge: Patrick Stephens, 1982.

Spicer, Mark. 'Large-Scale Strategy and Compositional Design in the Early Music of Genesis', in Expression in Pop-Rock Music, ed. Everett. 77-111. 


\section{Spicer (Ac)cumulative Form in Pop-Rock Music}

'Ghosts in the Machine: Analysing Style in the Music of the Police'. Paper presented at the Annual Meeting of the Society for Music Theory, Toronto, 2000.

- 'British Pop-Rock Music in the Post-Beatles Era: Three Analytical Studies'. PhD dissertation, Yale University, 2001.

. 'Strategic Intertextuality in Three of John Lennon's Late Beatles Songs'. Paper presented at the Annual Meeting of the Society for Music Theory, Columbus, 2002.

Stump, Paul. The Music's All That Matters: a History of Progressive Rock. London: Quartet Books, 1997.

Tatom, Marianne. 'How to Disappear Completely: the Vanishing Subject in Radiohead's Kid A'. Paper presented at the Annual Meeting of the Society for Music Theory, Philadelphia, 2001.

Théberge, Paul. " "Plugged in": Technology and Popular Music', in The Cambridge Companion to Pop and Rock, ed. Simon Frith, Will Straw, and John Street. Cambridge: Cambridge University Press, 2001. 3-25.

Vail, Mark. Vintage Synthesizers: Groundbreaking Instruments and Pioneering Designers of Electronic Music Synthesizers. San Francisco: Miller Freeman, 1993.

Winkler, Peter. 'Writing Ghost Notes: the Poetics and Politics of Transcription', in Keeping Score: Music, Disciplinarity, Culture, ed. David Schwarz, Anahid Kassabian, and Lawrence Siegel. Charlottesville: University Press of Virginia, 1997. 169-203.

Zak, Albin J. The Poetics of Rock: Cutting Tracks, Making Records. Berkeley: University of California Press, 2001. 